\title{
Phytoassisted synthesis of magnesium oxide nanoparticles from Pterocarpus marsupium rox.b heartwood extract and its biomedical applications
}

Manne Anupama Ammulu1,2, K. Vinay Viswanath', Ajay Kumar Giduturi ${ }^{1}$, Praveen Kumar Vemuri ${ }^{3}$, Ushakiranmayi Mangamuri ${ }^{4}$ and Sudhakar Poda ${ }^{1 *}$ (iD

\begin{abstract}
Background: Unlike chemical techniques, the combination of metal oxide nanoparticles utilizing plant concentrate is a promising choice. The purpose of this work was to synthesize magnesium oxide nanoparticles (MgO-NPs) utilizing heartwood aqueous extract of Pterocarpus marsupium. The heartwood extract of Pterocarpus marsupium is rich in polyphenolic compounds and flavonoids that can be used as a green source for large-scale, simple, and ecofriendly production of MgO-NPs. The phytoassisted synthesis of MgO is characterized by UV-Visible spectroscopy, Xray diffraction (XRD), dynamic light scattering (DLS), Fourier transform infrared spectroscopy (FT-IR), scanning electron microscopy (SEM) with EDS (energy dispersive X-ray spectroscopy), and transmission electron microscopy (TEM).

Results: The formation of MgO-NPs is confirmed by a visual color change from colorless to dark brown and they displayed a wavelength of $310 \mathrm{~nm}$ in UV-Spectrophotometry analysis. The crystalline nature of the obtained biosynthesized nanoparticles are revealed by X-ray diffraction analysis. SEM results revealed the synthesized magnesium oxide nanoparticles formed by this cost-effective method are spherically shaped with an average size of $<20 \mathrm{~nm}$. The presence of magnesium and oxygen were confirmed by the EDS data. TEM analysis proved the spherical shape of the nanoparticles with average particle size of $13.28 \mathrm{~nm}$ and SAED analysis confirms the crystalline nature of MgO-NPs. FT-IR investigation confirms the existence of the active compounds required to stabilize the magnesium oxide nanoparticles with hydroxyl and carboxyl and phenolic groups that act as reducing, stabilizing, and capping agent. All the nanoparticles vary in particle sizes between 15 and $25 \mathrm{~nm}$ and obtained a polydispersity index value of 0.248 . The zeta-potential was measured and found to be $-2.9 \mathrm{mV}$. Further, MgO-NPs were tested for antibacterial action against Staphylococcus aureus (Gram-positive bacteria) and Escherichia coli (Gram-negative bacteria) by minimum inhibitory concentration technique were found to be potent against both the bacteria. The blended nanoparticles showed good antioxidant activity examined by the DPPH radical scavenging method, showed good anti-diabetic activity determined by alpha-amylase inhibitory activity, and displayed strong anti-inflammatory activity evaluated by the albumin denaturation method.

(Continued on next page)
\end{abstract}

\footnotetext{
* Correspondence: sudhakarpodha@gmail.com

'Department of Biotechnology, Acharya Nagarjuna University, Nagarjuna

Nagar, Guntur, Andhra Pradesh 522510, India

Full list of author information is available at the end of the article
}

\section{Springer Open}

(c) The Author(s). 2021 Open Access This article is licensed under a Creative Commons Attribution 4.0 International License, which permits use, sharing, adaptation, distribution and reproduction in any medium or format, as long as you give appropriate credit to the original author(s) and the source, provide a link to the Creative Commons licence, and indicate if changes were made. The images or other third party material in this article are included in the article's Creative Commons licence, unless indicated otherwise in a credit line to the material. If material is not included in the article's Creative Commons licence and your intended use is not permitted by statutory regulation or exceeds the permitted use, you will need to obtain permission directly from the copyright holder. To view a copy of this licence, visit http://creativecommons.org/licenses/by/4.0/. 
(Continued from previous page)

Conclusions: The investigation reports the eco-friendly, cost-effective method for synthesizing magnesium oxide nanoparticles from Pterocarpus marsupium Rox.b heartwood extract with biomedical applications.

Keywords: Magnesium oxide nanoparticles, Pterocarpus marsupium, Antioxidant activity, Antimicrobial activity, Antidiabetic activity, Anti-inflammatory activity

\section{Background}

Conventional methods have been used for many years, but research has shown that green synthesis methods are more efficient in generating nanoparticles with less possibilities of failure, inexpensive, and ease of characterization $[1,2]$. Due to their poisonous metabolites, physical and chemical methods to synthesize nanoparticles (NPs) have presented many stresses on the environment. Nanomaterial synthesis may be conducted using methods based on the template-assisted, vaporliquid-solid, colloidal micellar, sol-gel, and microwave process. Magnesium oxide nanoparticles (MgO-NPs) are usually synthesized by various magnesium salts being decomposed thermally [3]. The latter methodologies are not preferred because of the extreme conditions of reaction, the use of poisonous reagents, expensive facilities, high pressure, and the usage of conservative nonrenewable forms of energy [4]. However, MgO-NPs prepared using these conventional methods often contain a relatively small surface area and are therefore of low reaction rate [5]. In general, biochemicals like polysaccharides, enzymes, and vitamins found in micro-organisms such as bacteria [6], fungi [7], algae [8], and plants [9] could be utilized for the biosynthesis of nanoparticles $[10,11]$.

Plant-based NP synthesis is not a difficult process; a metal salt is synthesized with plant extract and the process is completed at normal room temperature in minutes to a couple of hours. Especially for silver $(\mathrm{Ag})$ and gold ( $\mathrm{Au}) \mathrm{NPs}$ (nanoparticles), which are more stable when opposed to other metallic NPs, this technique has gained even more interest over the last decade. It can be effortlessly scaled up to generate NPs from green techniques and they are also fiscally smart. The greenly designed NPs are preferred over generally produced NPs in terms of their exceptional properties. The usage of additional chemicals which are hazardous and detrimental to human safety and the atmosphere could increase the reactivity and toxicity of the particles which may induce unintended adverse health effects due to their lack of consistency and compositional uncertainty [12, 13]. Green synthesis approaches are dramatically desirable provided their ability to reduce NP toxicity.

Nanotechnology is the field of science that investigates nano-range products, usually between 1 and $100 \mathrm{~nm}$. This is a technology that operates at the nanoscale and brings the varied areas of science such as pharmaceuticals, dentistry, and bio-engineering [14, 15]. Green chemistry strategy is important for nanomaterials potential prospects. This field of nanoscience will ultimately result in the production of healthy, environmentally sustainable NPs, and be widely adopted in nanotechnology $[16,17]$. The two significant methods for amalgamating NPs are "top-down" and "bottom-up" approaches using different methods such as crushing, sputtering, milling, thermal/laser ablation, etc. Suitable bulky content is broken down into small, fine particles in the top-tobottom approach, while NPs are synthesized in the bottom-to-top strategy using biological and chemical methods through the self-assembly of atoms into new nuclei that develop into nanosize particles, whereas the bottom-up approach involves chemical reduction and electrochemical methods [18].

Metal oxides are of considerable concern to scientists, because of their improved surface composition and high surface area. Magnesium oxide $(\mathrm{MgO})$ is one of the most important metal oxides with a wide range of applications in the catalysis [19-21] refractory materials [22], paint [23] and superconducting industries [24], biological, electrochemical, and medical fields [25]. Metal nanoparticles (NPs) have various applications in the biological, electrochemical, environmental [26-29], and medical fields [25] due to their specific properties such as large surface area to volume ratio, optical, magnetic [30], high surface energy compared to their bulk counterparts. Among different nanoparticles of metal oxide semiconductors $\left(\mathrm{ZnO}, \mathrm{SnO}_{2}, \mathrm{WO}_{3}, \mathrm{TiO}_{2}\right.$, etc.), magnesium oxide nanoparticles (MgO-NPs) earned considerable significance in the area of gas sensors due to their specific chemical and physical properties [31]. $\mathrm{MgO}$ is a major inorganic oxide and is considered a healthy substance for humans. $\mathrm{MgO}$ is used in the medical sector to treat different ailments as an antacid for heartburn and sore stomach [32]. In contrast to all other nanoparticles, magnesium oxide is very important because they have unique characteristics compared to bulk materials. Metal-based nanomaterials target several sites in living systems, and may also reduce the risk of growing drug resistance [16].

The excellent properties of $\mathrm{MgO}$ nanoparticles made them unique include high chemical stability, high photocatalytic activity, high electrical permittivity, non- 
toxicity, etc. Magnesium nanoparticles may have longlasting antibacterial action due to its low volatility and high-temperature tolerant properties [33]. Based on the literature, synthesis of MgO-NPs with neem leaves [34], Parthenium [35], citrus lemon extract [36], Brassica oleracea, and Punica granatum peels [37] are available. Biological nanoparticles have been found safe, ecologically responsible, cost-effective, and ensures the complete removal of toxic chemicals [38]. Therefore, the green synthesis is still an unexplored area to achieve MgO-NPs, and it provides numerous research possibilities. Among the metal oxide nanoparticles, zinc oxide and magnesium oxide nanoparticles have obtained considerable focus, due to their unique biochemical and physicochemical and properties. Similarly, magnesium $(\mathrm{Mg})$ is also a vital component for the development of the plant, acting as a powerhouse during the photosynthesis process. These nutrients, in comparison to the bulk, interact strongly with plants at the nano level by substantial absorption and accumulation. Thus, MgO-NPs has applications even in agriculture [39, 40].

Because of the abundance of effective phytochemicals in different plant extracts, plant biodiversity was commonly considered for the production of metal/metal oxide nanoparticles. Such constituents can reduce metal salts to metal nanoparticles [41]. The specific characteristics of these nanomaterials are explored for use in diagnostics, biomedical, antimicrobials, molecular signaling, catalysis, optical imaging, and biological device labeling [42]. The phytochemicals found in plant leaf extracts have an exceptional ability to minimize metal ions in a much shorter period compared to bacteria and fungi, allowing longer time for incubation. Thus, plant leaf extracts are considered the most suitable and beneficial route for both metal and metal oxide nanoparticle synthesis. Plant leaf extract plays a dual function by serving as both reduction and stabilization agents in the nanoparticle synthesis cycle to enable the synthesis of nanoparticles [43].

The plant leaf extract composition is also a vital aspect in the production of nanoparticles, for example, various plants produce differing amounts of phytochemicals. The major plant phytochemicals are flavones, terpenoids, carbohydrates, aldehydes, ketones, amides, and carboxylic acids, which are responsible for nanoparticle bioreduction [44]. Flavonoids have different biological groups and are better able to suppress metal ions. According to tautomeric transitions in flavonoids, the reactive hydrogen atom is released from which enol-form is transformed into the keto shape. This cycle is achieved by converting metal ions to metal nanoparticles. In sweet basil (Ocimum basilicum) extracts, the main element in the synthesis of biogenic silver nanoparticles is the enol- to keto-transformation [45]. Plant extracts are made up of biomolecules of carbohydrates and proteins, which serve as a reduction agent to encourage the generation of metallic nanoparticles [10].

Pterocarpus marsupium Roxb is a large tree, grown widely on the eastern, western, and southern parts of India and Sri Lanka, from the Leguminosae family known as Vijaysar or Bijasar. Several parts of the P. marsupium tree (bark, heartwood, leaves, and flowers) have been used for medicinal purposes in Ayurveda for many years. Rajgovind [46] examined the usage of Pterocarpus marsupium heartwood for the production of metallic oxide nanoparticles and tested their efficacy against Gram-positive bacteria and Gram-negative bacteria. It has long been shown that heartwood is beneficial for diabetes [47], and is used to relieve inflammation. There has been reported antidiabetic, antihyperlipidemic, and antioxidant activity of flavonoids and phenolic content in the tree [48]. According to conventional reports, Pterocarpus marsupium heartwood is the potential source of drugs utilized as an anti-inflammatory, astringent, antihelmintic, diabetes, leprosy, skin disease, diarrhea, bronchitis, asthma, and hair grayness.

The most important bioactive components are terpenoids, saponins, flavonoids, tannins, phenolic compounds, and alkaloids. Recently, furthermore, three major phenolic constituents isolated from the $P$. marsupium heartwood are marsupin, ptrerosupin, and pterostilbene [49]. Marsupin and pterostilbene substantially reduced hyperglycemic rat blood glucose levels [50]. Rastogi and Mehrotra [51] isolated 6-6 glucoside tetrahydroxyisoflavone $5,7,2-4$, which is a powerful antioxidant thought to prevent heart diseases. So many of these isolated compounds can serve as a potential supply of natural antioxidants from the different parts of the extract of $P$. marsupium. The plant's heartwood juice is considered to contain polyphenolic compounds (such as diphenyl propane flavonoids, sesquiterpenes, and derivatives), which exhibit high antioxidant, anti-inflammatory, antidiabetic, antimicrobial, and anticancer activity, and is used to treat diabetes, jaundice, ulcer, gastritis, and so on [52]. This plant was chosen for its high content of flavonoids and phenolics. Flavonoids have been described as crucial for the green synthesis of nanoparticles [53].

In the context of the above discussion, the current research investigates the synthesis of MgO-NPs by using P. marsupium heartwood extract and their biomedical applications. This is the first research to determine the impact of green synthesized MgO-NPs on antidiabetic and anti-inflammatory behaviors, to the best of our knowledge. This study thus offers an efficient, inexpensive, benign means for the production of metal nanomaterials with their therapeutic applications. 


\section{Methods}

\section{Collection of plant}

The plant Pterocarpus marsupium heartwood was collected from Tirupati area and was identified and authenticated by Dr. K. Madhava Chetty, Assistant Professor, Department of Botany, Sri Venkateswara University, Tirupati (Voucher no. 1587 has been deposited in a herbarium). The field studies were conducted in accordance to the local legislations and have taken necessary permissions. The plant was subsequently washed, dried in shade, subjected to fine grinding, and placed in a dry place in an airtight container.

\section{Preparation of $P$. marsupium heartwood aqueous extract} For $30 \mathrm{~min}, 50 \mathrm{~g}$ of coarse powder was boiled in $500 \mathrm{~mL}$ of distilled water. Then aqueous extract was cooled, filtered with a Whatman No. 1 filter paper, and refrigerated for further use.

\section{Total phenolic content}

The total phenolic content (TPC) was estimated spectrophotometrically with the Folin-Ciocalteu reagent using gallic acid as standard [54]. P. marsupium aqueous heartwood extract $(2 \mathrm{~mL})$ was combined with a diluted reagent of $10 \mathrm{~mL}$ Folin-Ciocalteu (1/10 with distilled water). Eight milliliters of sodium carbonate was further added to the solution after incubation for $2 \mathrm{~min}$. The process solutions were then kept for $2 \mathrm{~h}$ with occasional shaking at $37{ }^{\circ} \mathrm{C}$ in the dark. Estimated absorbance to be $765 \mathrm{~nm}$, at which a standard curve was made by taking gallic acid, at a concentration range of 50 to $500 \mu \mathrm{g} / \mathrm{mL}$. The findings are calculated in $\mu \mathrm{g}$ of an equivalent gallic acid (GAE) per $\mathrm{mL}$ of $P$. marsupium extract. All tests are carried out in triplicate

\section{Total flavonoid content}

The aluminum chloride colorimetric method was used for the calculation of flavonoid content in P. marsupium aqueous extract [55]. One milliliter of $P$. marsupium heartwood extract $(50 \mathrm{mg} / \mathrm{mL})$ was mixed with $4 \mathrm{~mL}$ of distilled water and $0.3 \%$ sodium nitrate was mixed. The reaction solution was subsequently incubated for $10 \mathrm{~min}$ and $0.3 \%$ of aluminum chloride was added and the solution was maintained for $6 \mathrm{~min}$. After which, $1 \mathrm{~mol} / \mathrm{L}$ of $2 \mathrm{~mL}$ sodium hydroxide solution was mixed, adding up to $10 \mathrm{~mL}$ of the final amount with the distilled water to the reaction mixture. The mixture remained in position for another $15 \mathrm{~min}$, and the absorption was estimated at $415 \mathrm{~nm}$. The total flavonoid content (TFC) was calculated from the calibration curve of quercetin $(10-50 \mu \mathrm{g} /$ $\mathrm{mL}$ ) as standard, and the result was expressed as $\mathrm{mg}$ quercetin equivalent (QE) per g of dry extract weight.

\section{Biosynthesis of $\mathrm{MgO}$ nanoparticles}

The magnesium oxide nanoparticles are synthesized according to Gaurav. S [56] with slight modifications. Thirty milliliters of $P$. marsupium extract prepared has been added dropwise to a $150 \mathrm{~mL}$ of freshly prepared magnesium nitrate solution and $1 \mathrm{M} \mathrm{NaOH}$ was also added dropwise at $80{ }^{\circ} \mathrm{C}$ for $6 \mathrm{~h}$ under continuous stirring using a magnetic stirrer. The modification of color from colorless to brown observed with the addition of magnesium nitrate solution determines the production of nanoparticles. The prepared mixture was then centrifuged at 12,000 rpm for $30 \mathrm{~min}$ and the collected pellet was washed several times with ethanol to eliminate any impurities and was calcinated at $400{ }^{\circ} \mathrm{C}$ in a furnace to extract dried MgO-NPs.

\section{Characterization of MgO-NPs}

Biosynthesized $\mathrm{MgO}$ nanoparticles and $P$. marsupium heartwood extract and plant extract are characterized by the UV-visible spectroscopy (Shimadzu, Tokyo, Japan). One milliliter of Pterocarpus marsupium wood extract was taken in a $10 \mathrm{~mL}$ flask and diluted with purified water and phosphate buffer at $\mathrm{pH} 7.4$ was taken as blank and UV-visible spectra are obtained in the range of 200$800 \mathrm{~nm}$. The surface morphological characteristics such as shape, size, and composition of MgO-NPs are monitored by scanning electron microscopy-energy-dispersive X-ray spectroscopy (SEM-EDX) using Zeiss SEM machine with spectral imaging system and transmission electron microscopy (TEM) using FEI-Tecnai G2 20 Twin, VIT university. The test sample (MgO-NPs) for SEM investigation was developed by placing the filtered lyophilized nanoparticles on the network, which was allowed to dry under a mercury light after $10 \mathrm{~min}$ of drying for SEM study. Test for TEM investigation was developed by placing a small drop of suspended nanoparticles on a carbon-covered copper network and enabling the dissipation of water into a vacuum dryer. TEM images were scanned on the grid containing MgO-NPs. MgO-NPs sample analysis by X-ray diffraction (XRD) was performed on a Miniflex 600 Powder XRD instrument, Osmania University operating at $40 \mathrm{kV}$ with a current of $30 \mathrm{~mA}$ using $\mathrm{Cu} \mathrm{Ka}$ at a scanning range of 10-80. Fourier transform infrared spectroscopy was carried out to examine the formation of magnesium oxide nanoparticles mediated by the functional groups in $P$. marsupium. The spectra of the considerable number of test samples (MgO-NPs, $\mathrm{PE}$ ) was reported by $\mathrm{KBr}$ pellet production at room temperature spectrometrically (Shimadzu FT-IR spectrophotometer). The range was preserved at a resolution of $4 \mathrm{~cm}^{-1}$, between 4000 and 400 $\mathrm{cm}^{-1}$. FTIR analysis was conducted to classify the biomolecules essential for capping and stabilizing synthesized metal nanoparticles. Zeta potential, particle size, 
and particle size distribution of magnesium oxide nanoparticles were measured using a particle size analyzer based on laser light scattering (Zetasizer NS 3000, Malvern Instruments). To avoid aggregation, the freshly made solution containing MgO-NPs is dispersed in distilled water was ultra-sonicated at $90 \%$ amplitude of probe for $10 \mathrm{~min}$. MgO-NPs are dispersed in water at a concentration of $40 \mu \mathrm{g} / \mathrm{mL}$, and mixing was performed by probe sonication for $10 \mathrm{~min}$ just before estimation. The lyophilized form of MgO-NPs is dispersed in water to achieve the appropriate spreading intensity of nanoparticles. Malvern zeta-size analyzer has calculated the particle size. The zeta potential was calculated using Zeta Sizer (Malvern Instruments) with polycarbonate cells with gold-plated electrodes, and utilizing water as a source for sample preparation. Zeta potential defines the surface potential of magnesium oxide nanoparticles, which is important for characterizing nanoparticle stability. The study was performed in triplicate fashion, and average values were reported with standard deviation.

\section{Minimum inhibitory concentration}

The test microorganisms include Gram-positive bacteria Staphylococcus aureus (MTCC 3160), Gram-negative bacteria Escherichia coli (MTCC 1683). According to Shaghufta Perveen [57], minimum inhibitory concentration (MIC) of plant extract, and magnesium oxide nanoparticles synthesized with Pterocarpus marsupium were determined using the broth dilution process. Sterilized nutrient broth $(5 \mathrm{~mL})$ was taken into each test tube for minimum inhibitory concentration assay and inoculated with $100 \mu \mathrm{L}$ of the freshly made test strain. Next, various concentrations of Pterocarpus marsupium (PM), and biogenic MgO-NPs $(5,10,15,20,25,30,35 \mu \mathrm{L})$ are added in the test tubes and incubated under an orbital shaker with $120 \mathrm{rpm}$ for $24 \mathrm{~h}$ at $37{ }^{\circ} \mathrm{C}$. After $24 \mathrm{~h}$, each test tube was evaluated for turbidity at $600 \mathrm{~nm}$ using a Spectrophotometer. The bacterial colonies were concurrently treated with $\mathrm{MgO}-\mathrm{NPs}$, control (i.e., sterile media devoid of test solution), and blank (i.e., sterile media devoid of inoculums). MIC has been described to be the lowest MgO-NPs concentration inhibiting bacterial growth. All the assays were conducted in triplicates.

\section{Antioxidant activity}

$\mathrm{MgO}-\mathrm{NPs}$ with $P$. marsupium extract were tested for their ability to neutralize radical PPP (2,2-diphenyl-1picrylhydrazyl), which was demonstrated by a reduction in DPPH methanol solution absorbed in the reaction [58]. The testing methods are focused on the analysis of anti-oxidation in MgO-NPs, which are synthesized with Pterocarpus marsupium extract. Different dilutions are prepared between 10 and $320 \mu \mathrm{g} / \mathrm{mL}$. To calculate the changes in the absorption rate, a spectrophotometer was used. Each test tube was kept 30 min away from light. The dilutions were combined with $1.0 \mathrm{~mL}$ of DPPH reagent at $0.1 \mathrm{mM}$ concentration in methanol. The DPPH reagent was set up $24 \mathrm{~h}$ in advance. The absorption was examined at a wavelength of $515 \mathrm{~nm}$ followed by $30 \mathrm{~min}$ of shaking. Next, taken $1 \mathrm{~mL}$ of water and methanol in each test tube and were used as reference. The absorption of the DPPH solution was calculated before measuring sample absorbance. The sample represented free DPPH radicals scavenging activity as a percentage of free radical inhibition and was measured using the following formula:

$$
\text { \%inhibition }=\frac{A_{O}-A_{t}}{A_{T}} \times 100
$$

where $A_{0}$ was the control absorbance and where $A_{\mathrm{t}}$ was the absorbance in the sample presence. All experiments were run in triplicate, and mean values were plotted on the graph.

\section{Alpha-amylase inhibition activity}

Alpha-amylase is an enzyme which helps to split large, insoluble molecules of starch into soluble molecules found in pancreatic juice and saliva. Different concentrations of prepared $\mathrm{MgO}-\mathrm{NPs}$ were taken in various testing tubes from 1 to $5 \mathrm{mg}$ and the volume was developed up to $0.5 \mathrm{~mL}$ with a phosphate buffer of $\mathrm{pH}$ 6.9. By using $1 \mathrm{~mL}$ of phosphate buffer, a blank was measured. Then $0.5 \mathrm{~mL}$ of $\alpha$-amylase $(0.5 \mathrm{mg} / \mathrm{mL})$ was added to the solution. Thereafter, the solution was incubated for $10 \mathrm{~min}$ at $25{ }^{\circ} \mathrm{C}$. Subsequently mixed, $0.5 \mathrm{~mL}$ of $1 \%$ starch solution into $0.02 \mathrm{M}$ sodium phosphate buffer of $\mathrm{pH} 6.9$ to all test tubes and incubated for $10 \mathrm{~min}$ at 25 ${ }^{\circ} \mathrm{C}$. The reaction was halted by introducing $1.0 \mathrm{~mL}$ DNS, and the reaction mixture was kept in a boiling water bath for $5 \mathrm{~min}$ and cooled to room temperature. The solution was made with distilled water up to $8 \mathrm{~mL}$, and the absorbance was read in the spectrophotometer at 540 $\mathrm{nm}$ against a blank solution [59]. The percentage inhibition of $\alpha$-amylase enzyme was calculated using the formula:

$$
\text { Inhibition }(\%)=100 \times[\text { Control }- \text { Test/Control }]
$$

\section{Inhibition of albumin denaturation}

The reaction mixture $(5 \mathrm{~mL})$ consisting of $0.2 \mathrm{~mL}$ of egg albumin (fresh hen's egg), $2.8 \mathrm{~mL}$ of phosphate-buffered saline (pH 6.4), and $2 \mathrm{~mL}$ of varying extract concentrations to exceed $20,40,60,80,100 \mu \mathrm{g} / \mathrm{mL}$ of final concentrations. Similar volume of double distilled water was served as control. The mixtures were then incubated in a Biological oxygen demand incubator at $\left(37 \pm 2{ }^{\circ} \mathrm{C}\right)$ for $15 \mathrm{~min}$, and then heated for $5 \mathrm{~min}$ at $70{ }^{\circ} \mathrm{C}$. Their 
absorption was estimated at $660 \mathrm{~nm}$ after cooling using the blank. Dicflonec sodium was used as a standard drug at final concentrations and tested equally for absorbance calculation [60]. The percentage inhibition of albumin denaturation was calculated by using the formula:

$$
\text { \%inhibition }=100 \times\left(\left[V_{t} / V_{c}\right] .-1\right.
$$

where $V_{\mathrm{t}}=$ absorbance of the test sample and $V_{\mathrm{c}}=\mathrm{ab}$ sorbance of control

\section{Results}

\section{Total phenolic content}

The total phenolic content of $P$. marsupium heartwood extract was calculated spectrophotometrically using Folin-Ciocalteu reagent and was expressed as $\mathrm{GAE} / \mathrm{mL}$ of plant extract. The standard gallic acid curve was used to estimate the actual quantity of phenolic compounds in heartwood extract. Phenolic content in the test sample was found to be $89.76 \pm$ $1.7 \mathrm{GAE}$ per $\mathrm{mL}$.

\section{Total flavonoid content}

The complete flavonoid content of $P$. marsupium aqueous extract was evaluated using an aluminum chloride procedure. The standard quercetin curve was used to calculate the actual quantity of flavonoid compounds in heartwood extract. Flavonoid content in the test sample was found to be $54.34 \pm 1.2 \mu \mathrm{g} \mathrm{QE}$.

\section{Physical appearance and UV spectroscopy analysis of phytoassisted MgO-NPs}

During the formation of magnesium oxide nanoparticles synthesized from aqueous heartwood extract of Pterocarpus marsupium, the colorless magnesium nitrate solution changed to dark brown as shown in Fig. 1a. The prepared phytosynthesized magnesium oxide nanoparticles and P. marsupium extract were confirmed by UVVis spectroscopy. At room temperature, for $24 \mathrm{~h}$ the prepared nanoparticle solution was kept aside. The UVvisible $\mathrm{MgO}-\mathrm{NPs}$ synthesized with $P$. marsupium heartwood extract after $24 \mathrm{~h}$ showed in Fig. 1b. The absorption peak at $310 \mathrm{~nm}$ indicates that $\mathrm{MgO}-\mathrm{NPs}$ are synthesized. Therefore, it was evident that $\mathrm{Mg}\left(\mathrm{NO}_{3}\right)_{2}$ was reduced to $\mathrm{MgO}$. The UV-Vis spectrum of plant extract shows a wavelength at $281 \mathrm{~nm}$ (Fig. 1c).

\section{XRD analysis}

Figure 2 shows the XRD pattern of magnesium oxide nanoparticles obtained with Pterocarpus marsupium heartwood extract. After the reaction, the intense diffraction peaks at $2 \theta$ values of $37.76^{\circ}, 43.12^{\circ}, 64.97^{\circ}$,

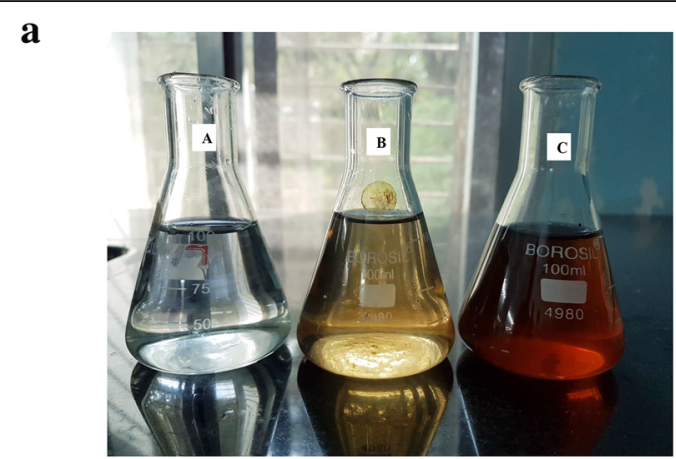

b

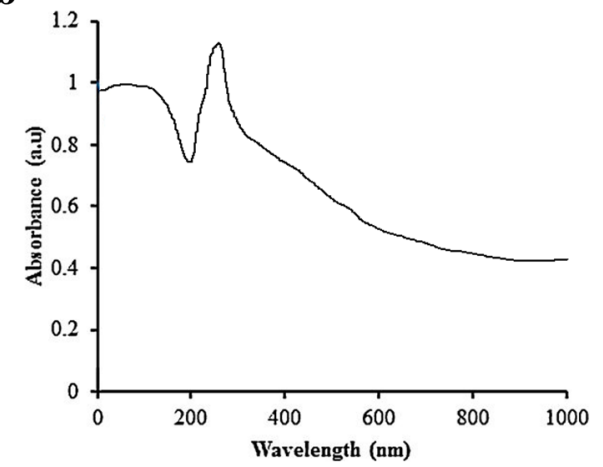

c

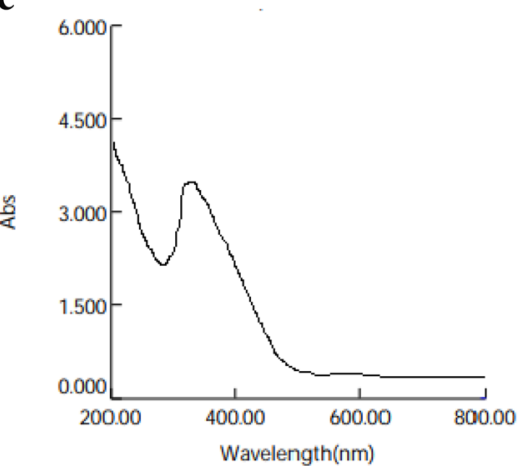

Fig. 1 a A: magnesium nitrate solution, B: before the synthesis of nanoparticles, C: after synthesis of nanoparticles. b UV-Visible spectrophotometric analysis of biosynthesized magnesium oxide nanoparticles. c UV-Visible spectrophotometric analysis of Pterocarpus marsupium heartwood extract 
$74.45^{\circ}$, and $78.12^{\circ}$ assigned to the (111), (220), (220), (311), and (222) planes of a faced center cubic (FCC) lattice of magnesium respectively and suggest that the magnesium oxide nanoparticles are crystalline [61]. The patterns comply well with standard diffraction data of magnesium oxide nanoparticles (JCPDS file No. 894248). On the diffraction peaks with the Debye-Scherrer equation below, the average crystallite dimension was calculated. In particular, there are only a few other peaks in the spectrum which indicates the lack of metallic impurities.

$$
D=k \lambda(\beta \cos \theta)
$$

where $D$ is the particle size of the crystal, $k$ is the Sherrer constant (0.9), $\lambda$ is the X-ray wavelength $(0.15406 \mathrm{~nm}), \beta$ is the width of the XRD peak at half-height, and $\theta$ is the Bragg diffraction angle.

\section{FT-IR spectroscopic analysis}

Fourier transform infrared spectroscopy (FT-IR) studies of magnesium oxide nanoparticles synthesized from Pterocarpus marsupium extract and plant extract were performed to characterize the chemical nature of the nanoparticles as shown in Fig. 3. The study shown sharp absorption peaks at 3400 to $3300,3356,645$, and 524, $1625 \mathrm{~cm}^{-1}$ for plant extract (Fig. 3a) and intense peaks of MgO-NPs are shown at 3400 to 3300, 3396, 2924, 1029, 1625,1633, 405, 416, and $441 \mathrm{~cm}^{-1}$ (Fig. 3b). The FT-IR response proves the existence of alkaloids, phenolic compounds, amino acids, flavonoids in the Pterocarpus marsupium heartwood extract.

\section{Zeta potential, particle size, and PDI of MgO-NPs}

Using a dynamic light scattering technique, the mean particle size, polydispersity index (PDI), and zeta potential of $\mathrm{MgO}$ nanoparticles synthesized using Pterocarpus marsupium were studied. The surface charge of biosynthesized $\mathrm{MgO}$ nanoparticle was measured at zeta potential of $-2.9 \mathrm{mV}$ using dynamic light scattering (DLS) was graphically represented (Fig. 4b). The average size of MgO-NPs synthesized from P. marsupium is $25 \mathrm{~nm}$ (Fig. 4a). The PDI value of MgO-NPs synthesized from Pterocarpus marsupium is 0.248 .

\section{SEM studies of MgO-NPs}

Once the size of the nanoparticle was confirmed, it was subjected to electron microscopy for detailed morphological studies. The scale at $10 \mu \mathrm{m}$ (Fig. 5a) of magnesium oxide nanoparticles synthesized using $P$. marsupium heartwood extract along with energydispersive X-ray spectroscopy (EDS) profiles are shown in Fig. 5c, which indicates the MgO-NPs presence, with peaks at between 0.5 and $1.5 \mathrm{kV}$. To investigate the average size of the nanoparticles, the histogram analysis was performed (Fig. 5b). In contrast, the MgO-NPs are spherical, well scattered showing a large surface area to volume ratio, integrated, and bigger clusters are formed.

\section{TEM analysis of MgO-NPs}

The TEM images of biosynthesized $\mathrm{MgO}$ nanoparticles have been shown (Fig. 6). In the low magnification

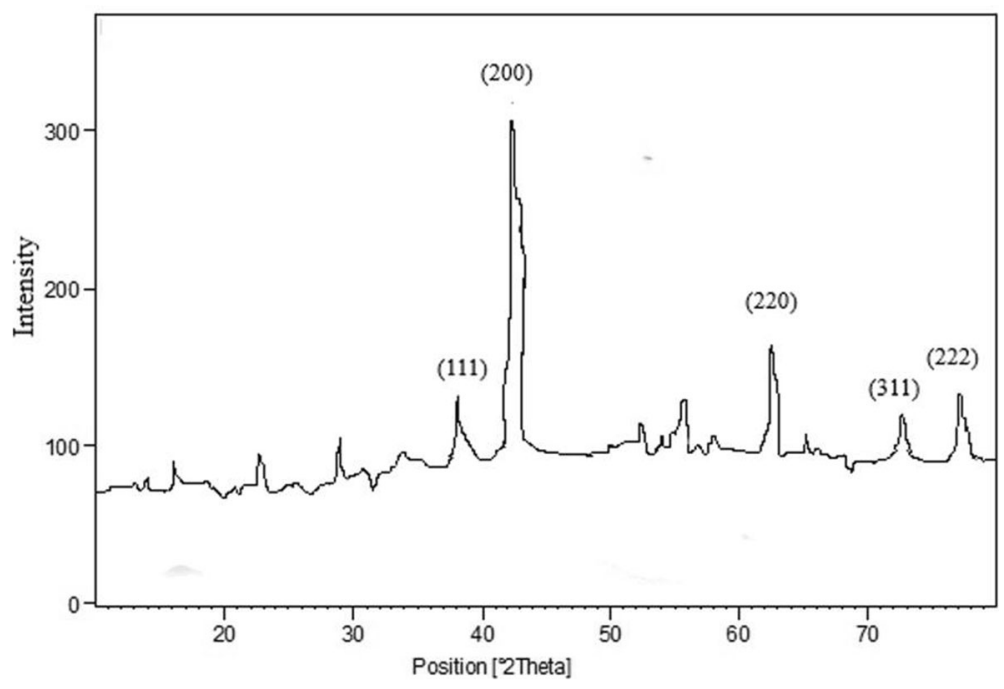

Fig. 2 XRD pattern of green synthesized MgO nanoparticles using P. marsupium heartwood extract 

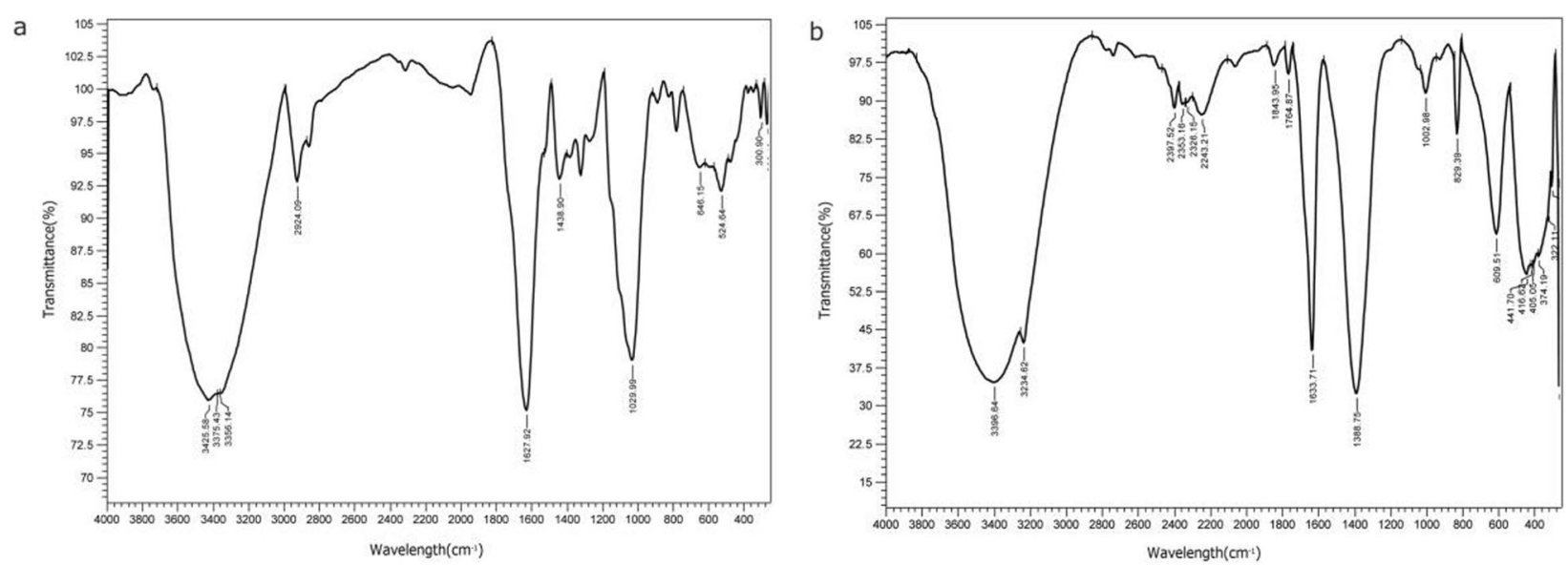

Fig. 3 a FTIR image of Pterocarpus marsupium heartwood aqueous extract. b FTIR image of Pterocarpus marsupium synthesized $\mathrm{MgO}$ nanoparticles

picture at a scale bar of $200 \mathrm{~nm}$ of single and cluster of $\mathrm{MgO}$ nanoparticles (Fig. 6a, b), it can be seen that all the particles were random in size and exhibit monodispersity, whereas under a highly magnified TEM micrograph at a bar of $200 \mathrm{~nm}$ (Fig. 6a), a reasonably good understanding of shape and size can be obtained; the size of the nanoparticle is between 10 and $20 \mathrm{~nm}$ and spherical shaped. Figure 6c displays selective area electron diffraction (SAED) patterns of a single $\mathrm{MgO}$ nanoparticle, where the white spot array supports the nanoparticle's crystalline nature.

\section{Biomedical applications of Pterocarpus marsupium synthesized MgO-NPs antioxidant activity by DPPH radical scavenging}

MgO-NPs synthesized with $P$. marsupium heartwood extract was determined to demonstrate antioxidant activity, with a radical DPPH sample (Fig. 7). The MgONPs scavenged free radicals dependent on concentration showed percentage inhibition at a minimum range of 10 $\mu \mathrm{g} / \mathrm{mL}$ at $22.34 \pm 1.65$ with a maximum range of 320 $\mu \mathrm{g} / \mathrm{mL}$ at $52.43 \pm 0.54$ respectively. This study was carried out by measuring the $\mathrm{IC}_{50}$ parameter for the $\mathrm{DPPH}$ scavenging activity of MgO-NPs synthesized with $P$. marsupium heartwood extract as shown in Table 1. This factor decides how free radicals can be scavenged. Increasing the $\mathrm{IC}_{50}$, the antioxidant is more reactive.

\section{Minimum inhibitory concentration}

MIC of developed MgO-NPs, PM, and control against Gram-positive and Gram-negative are shown in Table 2 and Fig. 8. The MIC values of MgO-NPs against both bacteria were found to be between 10 and $25 \mu \mathrm{g} / \mathrm{mL}$.

\section{Alpha-amylase inhibitory activity of MgO-NPs}

Figure 9 shows the effectiveness of MgO-NPs synthesized with $P$. marsupium in inhibiting $\alpha$-amylase. The percentage inhibition of $\alpha$-amylase by the MgO-NPs was

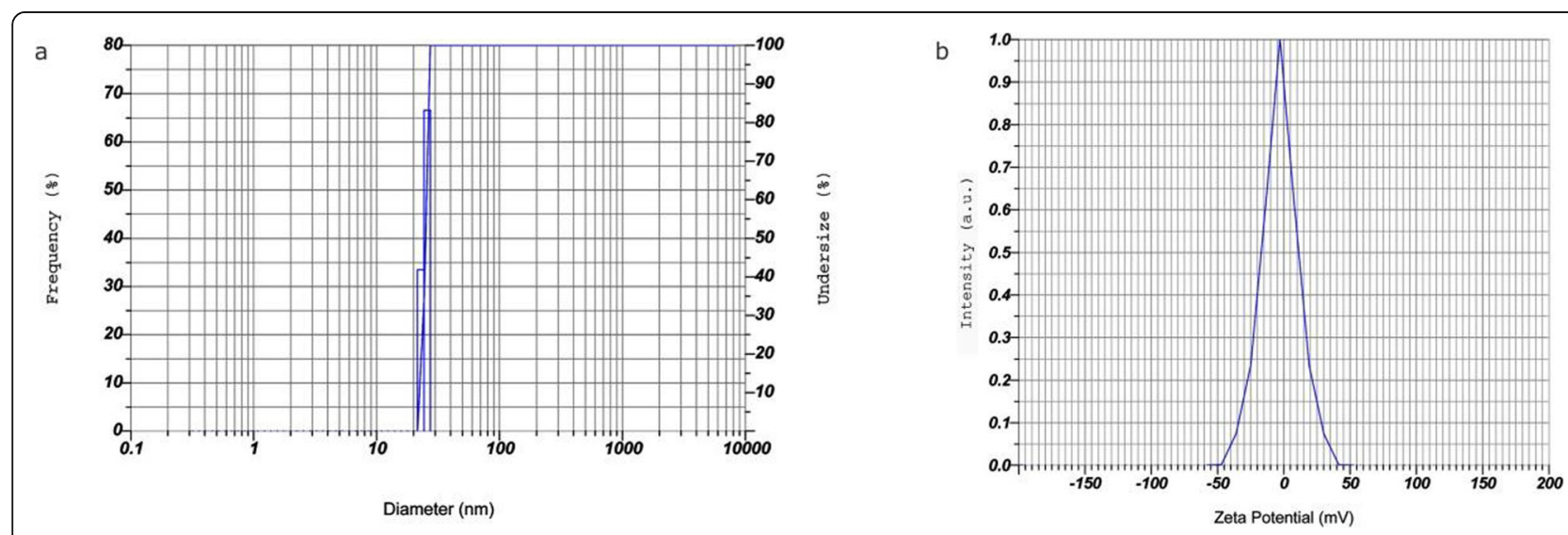

Fig. 4 a Particle size of the green synthesized MgO-NPs using P. marsupium heartwood extract. b Zeta potential of green synthesized MgO-NPs using P. marsupium heartwood extract 


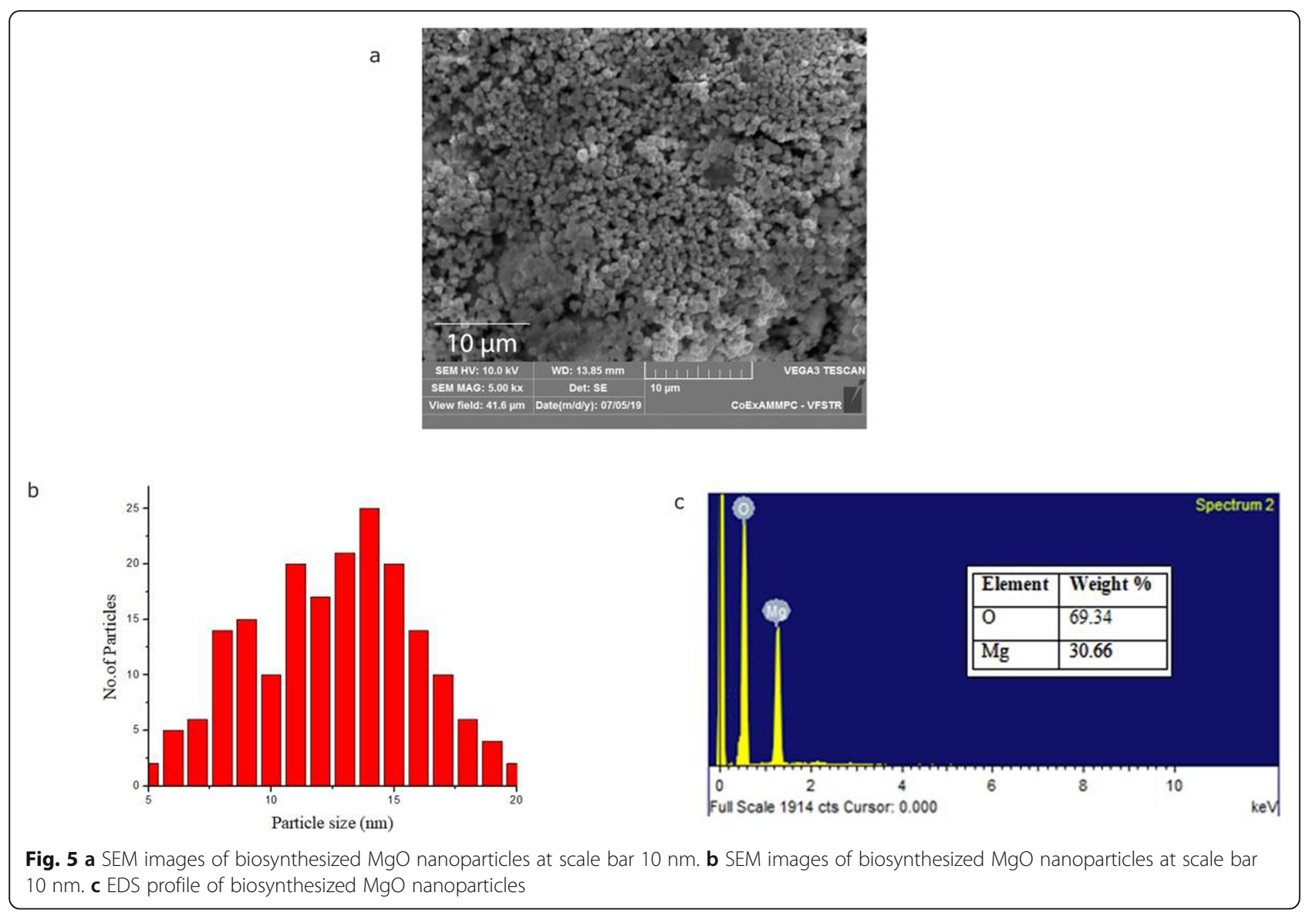

investigated within a concentration range of $20-100 \mu \mathrm{g} /$ $\mathrm{mL}$, and 56.32 was found to be the $\mathrm{IC}_{50}$ value as shown in Table 3.

\section{Effect on protein inhibition}

Denaturation of proteins is a common process of inflammation. In diabetes, the stimulation of cytokines activates the membrane inflammatory responses and tissue proteins. Protein denaturation levels are a measure of the severity of the inflammation. Results indicate that the MgO-NPs help inhibit the process of protein denaturation which therefore contributes to a decrease in the process of inflammation in patients with diabetes.

Figure 10 demonstrates the in-vitro anti-inflammatory activity of MgO-NPs on inhibiting protein denaturation. The minimum inhibition observed by the synthesized nanoparticles at $20 \mu \mathrm{g} / \mathrm{mL}$ concentration is $16.26 \pm 1.01 \%$. As shown in Table 4, the $\mathrm{IC}_{50}$ was found to be 81.69.

\section{Discussion}

\section{Characterization of MgO-NPs}

Physical appearance and UV spectroscopy analysis of phytoassisted MgO-NPs

A drop in the color intensity of the extract was observed as an initial confirmation of the creation of the $\mathrm{MgO}$ -
NPs. This is due to the fact that when undertaking the reduction and stabilization processes for the synthesis of nanoparticles, the phytochemicals of the plant extract were degraded [62]. The presence of a characteristic absorption band associated with MgO-NPs at $310 \mathrm{~nm}$ further supports the development of nanoparticles by the green method used, apart from the color transformation of the extract (from colorless to brown) (Fig. 1a). A single peak appearance in the UV-spectrum of MgO-NPs shows that the prepared NPs is iso-morphological [63].

The color modification is due to the phyto-reduction by the $P$. marsupium aqueous extract of the magnesium nitrate and is apparent for the successful biosynthesis of nanoparticles.

Phytochemical analysis proved the presence of glycosides, carbohydrates, flavonoids, tannins, saponins, phenolic compounds, and alkaloids in various parts of the plant. It is also a rich source of biomolecules like Epicatechin, marsupin, ptrosupin, pterostilbene, and 5,7,2-4 tetrahydroxy isoflavone 6-6 glucoside [38]. The result of $\mathrm{UV}-\mathrm{Vis}$ indicates that the reductive biomolecules in the heartwood extract were able to perform the task of bioreduction resulting in the formation of MgO-NPs. As shown in the Fig. $1 \mathrm{~b}$, the absorption peak lies in the range of $200-800 \mathrm{~nm}$. In this process, the lack of sharp 
a

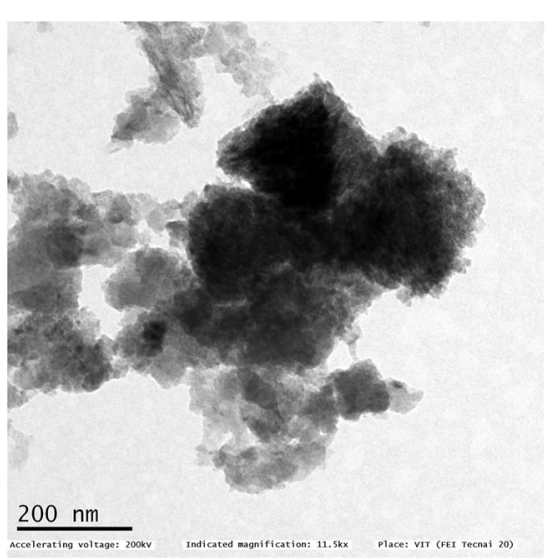

b

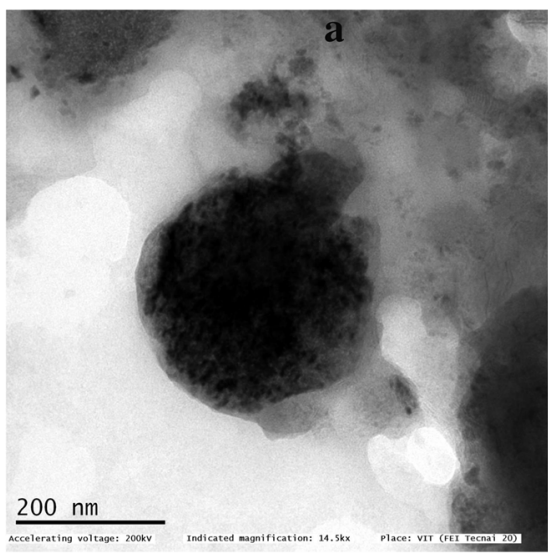

c

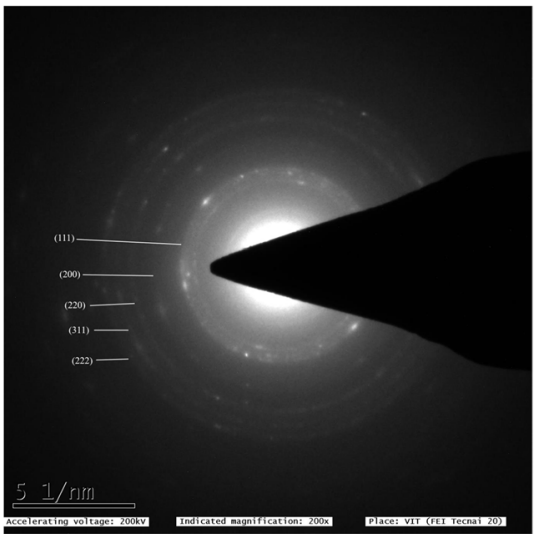

Fig. 6 a TEM micrograph of MgO nanoparticles synthesized with Pterocarpus marsupium heartwood extract at scale bar $200 \mathrm{~nm}$. b TEM micrograph of single $\mathrm{MgO}$ nanoparticle at scale bar $200 \mathrm{~nm}$. c SAED pattern of single magnesium oxide nanoparticle

peaks indicates the production of nanoparticles at different sizes and supports the findings of the visibleultraviolet spectrum and electron microscopy.

\section{XRD analysis}

The average crystalline size of the MgO-NPs produced from the values was determined to be $16.76 \mathrm{~nm}$. Individual crystallization of the capping agents was excluded out as part of the purification procedure due to the process of centrifugation and particle dispersion in water following the formation of nanoparticles. Also, the expansion of peaks in the stable XRD pattern is due to the influence of particle size.

\section{FT-IR spectroscopic analysis}

Because of the presence of alcoholic or phenolic groups the large peak can be seen in the area between 3400 and $3300 \mathrm{~cm}^{-1}$ in Fig. 3a and b. The infra-red band at 3356 $\mathrm{cm}^{-1}$ was shown in Fig. 3a for the $\mathrm{O}-\mathrm{H}$ bond vibrations of a hydroxy group, a slight decrease in peak intensity, and shift of the peak from $3356 \mathrm{~cm}^{-1}$ (Fig. 3b) to 3396 $\mathrm{cm}^{-1}$ in Fig. 3a indicates the role of organic molecules in the development of $\mathrm{MgO}$ nanoparticles. This broad peak at $3396 \mathrm{~cm}^{-1}$ helps to stabilize the particles crystal growth, while restricting the particles size and preventing them from agglomeration (Fig. 3b). The peak at 2924 $\mathrm{cm}^{-1}$ suggests stretching of alkynes (Fig. 3b). The strong band at 1029 was allocated to the $\mathrm{C}-\mathrm{O}$ stretching vibrations of alcohol. Additional peaks at 645 and 524 can be assigned to bending modes of aromatic compounds (Fig. $3 \mathrm{a})$. The band at 1408 is assigned to the methylene scissoring vibrations from the proteins. The most extreme peak at $1625 \mathrm{~cm}^{-1}$ and $1633 \mathrm{~cm}^{-1}$ indicates $\mathrm{C}=\mathrm{O}$, typical of the flavonoid structure found in the aqueous extract of Pterocarpus marsupium as shown in both Fig 3a and b. The absorption peak at $1388 \mathrm{~cm}^{-1}$ was subjected to $\mathrm{C}-\mathrm{H}$ bending vibrations of an aromatic tertiary amine group (Fig. 3a).

The peaks observed at 405, 416, and $441 \mathrm{~cm}^{-1}$ indicates the formation of MgO-NPs (Fig. 3b). Such peaks are observed due to vibrations of magnesium oxide. Likewise, $\mathrm{MgO}$ nanoparticles synthesized by Tamilselvi [64] generated large FT-IR transmission peaks at 449, 511,584 , and $671 \mathrm{~cm}^{-1}$, due to the presence of 103-105 


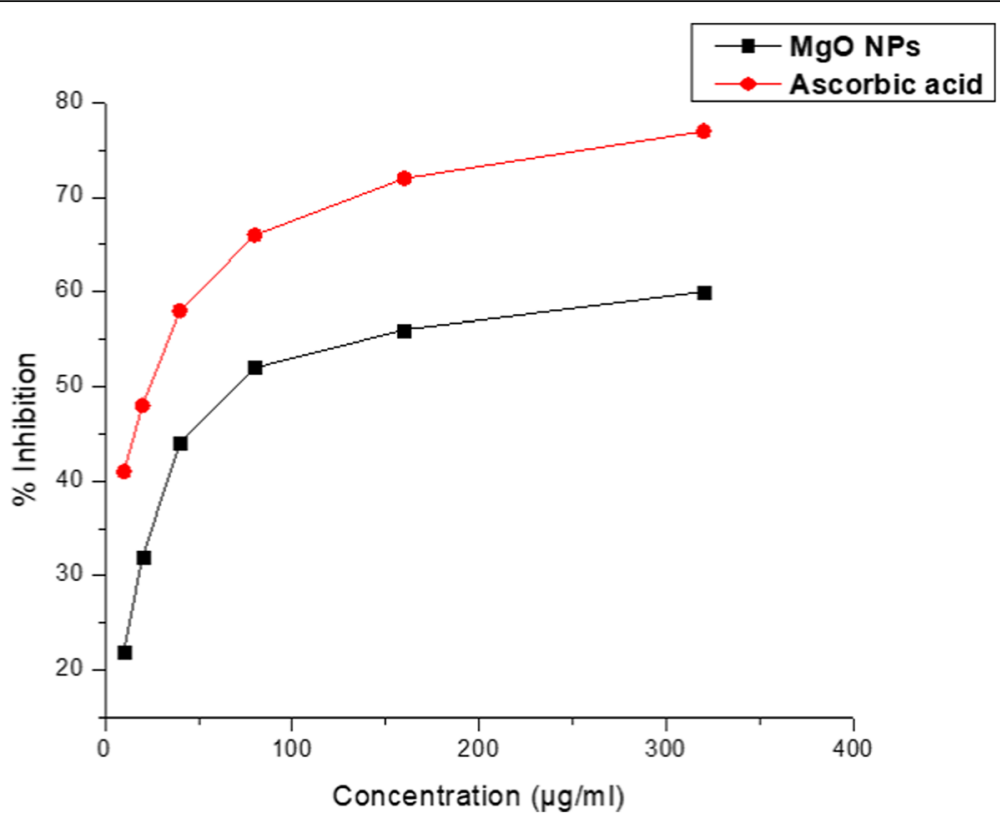

Fig. 7 DPPH radical scavenging activity of MgO nanoparticles synthesized with Pterocarpus marsupium heartwood aqueous extract

magnesium oxide vibrations. The variations and changes in $\mathrm{MgO}$ vibrations might be caused by interactions with functional groups of plant extracts or by the use of different precursors. The aliphatic compounds (Alkynes and alkanes) found in Pterocarpus marsupium is converted into aromatic amine groups because the magnesium precursor has nitrate in the solution for preparing $\mathrm{MgO}$ nanoparticles. This transition may be linked to variations, such as the oxidation, reduction, or degradation of phytochemical compounds during nanoparticle development [11]. The existence of bioactive compounds in PM was confirmed by FT-IR spectra. These bioactive compounds were assumed as reducing and capping contributors for MgO-NPs [65].

\section{Zeta potential, particle size, and PDI of MgO-NPs}

The existence of negatively charged oxide on the surface of the magnesium oxide particle indicates a negative zeta potentiality. Since magnesium oxide has oxygen on its surface that specifies its surface charge, it oxidizes the phytochemicals at their oxidation rate, where oxygen is crucial to the formation of magnesium oxide that defines particle stability [63]. All the particles vary in average sizes between 15 and $25 \mathrm{~nm}$. The degree of "non-

Table 1 In vitro antioxidant activity of MgO-NPs synthesized from Pterocarpus marsupium heartwood extract by DPPH radical scavenging

\begin{tabular}{ll}
\hline Sample & $\mathbf{I C}_{\mathbf{5 0}}(\boldsymbol{\mu \mathbf { g }} / \mathbf{m L})$ \\
\hline Ascorbic acid & 38.73 \\
MgO-NPs & 89.67 \\
\hline
\end{tabular}

uniformity" when particles are distributed in a solution is defined as polydispersity. The polydispersity index is a measure of a sample's dispersity in solution. A fully uniform sample will have a PDI of 0. PDI in the 0.2-0.6 range is appropriate because particle distribution is slightly polydisperse [66].

\section{SEM studies of MgO-NPs}

Aggregation of particles is may be due to the Van der Waal forces and interactions between the magnesium oxide nanoparticles [67]. All of nanoparticles are in the range between 5 and $20 \mathrm{~nm}$ (Fig. 6b). The average size of the MgO-NPs was calculated to be $11.68 \mathrm{~nm}$. The surface morphology presented has beneficial applications in catalysis [68] and medicine [69].

The signal properties of magnesium and oxygen were further investigated by the EDS profile. The EDS profile is supporting evidence of pure magnesium oxide nanoparticles. It shows the weight of magnesium at 30.66\% and of the weight of oxygen at $69.34 \%$. Graph shows the standard EDS profile of MgO. From the EDS graph, it is verified that the synthesized NPs are composed of only $\mathrm{Mg}$ and oxygen. We have not detected any other peaks, which again suggest that the synthesized NPs are pure MgO-NPs.

\section{TEM analysis of MgO-NPs}

Interestingly, TEM images show that most of the particles are not in direct contact but are divided by a relatively standardized inter-particle space. The presence of lines also indicates the crystallinity of $\mathrm{MgO}$ nanoparticles which was otherwise deficient in non- 
Table 2 Minimum Inhibitory Concentration values of MgO-NPs synthesized from P. marsupium heartwood extract against E. coli and S. aureus

\begin{tabular}{lccc}
\hline & Control & Pterocarpus marsupium Extract & Biogenic MgO-NPs \\
\hline E. coli & $3 \pm 0.139$ & $10 \pm 0.261$ & $24 \pm 0.439$ \\
MIC $(\mu \mathrm{g} / \mathrm{mL})$ & & $22 \pm 0.168$ \\
S. aureus & $5 \pm 0.121$ & $12 \pm 0.070$ & \\
MIC $(\mu \mathrm{g} / \mathrm{mL})$ & & & \\
\hline
\end{tabular}

Data represents the average of three experimental values \pm SD

metallic organic compounds and molecules. It is also evident from the pictures that the materials are agglomerated attributed to low stability. Particulate agglomeration can be minimized by adjusting the sample's $\mathrm{pH}$ to increase the electronegativity charge [70]. The TEM finding also follows SEM morphology (Fig. 5), which has demonstrated closer-size uniformity of particles. The calculation of the average particle size of the MgO-NPs from the SEM micrograph $(11.68 \mathrm{~nm})$ aided by ImageJ contrasts with that reported from the TEM micrograph $(13.28 \mathrm{~nm})$, thereby validating the size parameter of the MgO-NPs. The average size of $\mathrm{MgO}-\mathrm{NPs}$ synthesized using Chloromolaena odorata leaf extract was found to be 12.3 $\mathrm{nm}$, which is almost close to the size of NPs obtained in the current research [71].

Acquired TEM results can be compared with the results obtained by the synthesis of SAED pattern of single MgO-NP displayed in Fig. 6c shows concentric circles with intermittent bright spots corresponding to crystalline ring pattern for a facecentered cubic structure, suggesting the strong crystalline nature of the particles. SAED pattern with spots and spongy pattern also provides support for its polydisperse existence as well. The rings can be attributed to the diffraction from the $\mathrm{MgO}$ planes (111), (200), (220), (311), and (222) corresponding to the crystalline nature of nanoparticles. As verified by the XRD study, these TEM diffraction rings may be assigned for their respective $\mathrm{MgO}$ lattice planes. The properties showcased by the magnesium oxide nanoparticles might be the outcome of the effective capping capacity of the bioactive compounds present in the plant extract along with the UV irradiation passing through the test sample in ethanol medium, which enhanced particle dispersion and homogeneity [67].

\section{Antioxidant activity by DPPH radical scavenging}

This approach lowers the radical stable nitrogen 2, 2diphenyl-1-picrylhydrazyl (DPPH) present in the measured sample, resulting in a decrease in absorption measurably at $515 \mathrm{~nm}$. The oxygen-donating substances form the reduced DPPH, the solution thus loses its violet color. In this study, the effective radical solution is violet which shows that the earlier unknown electron is paired. The color change of the $\mathrm{DPPH}$ solution indicates its free radical scavenging property after application by the antioxidant solution. Standard ascorbic acid was taken as a control for the

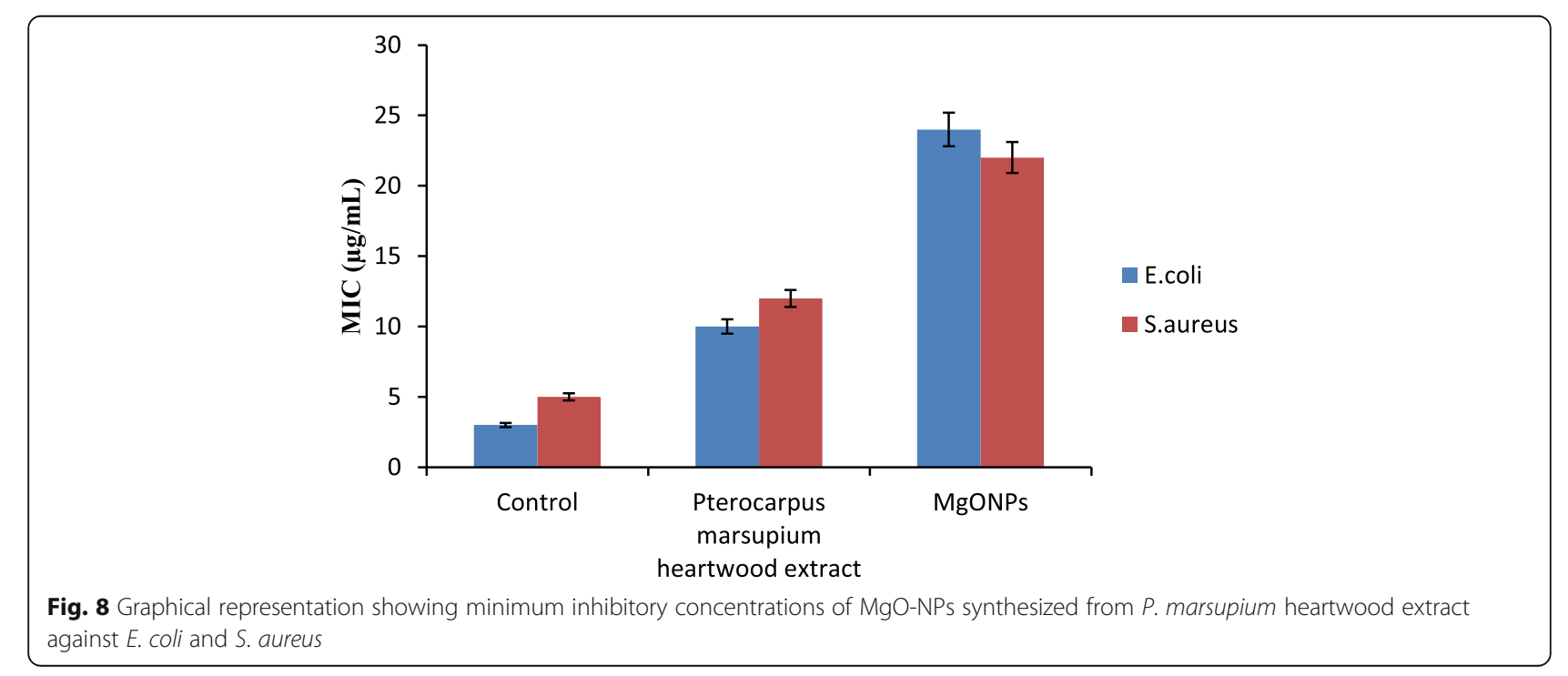




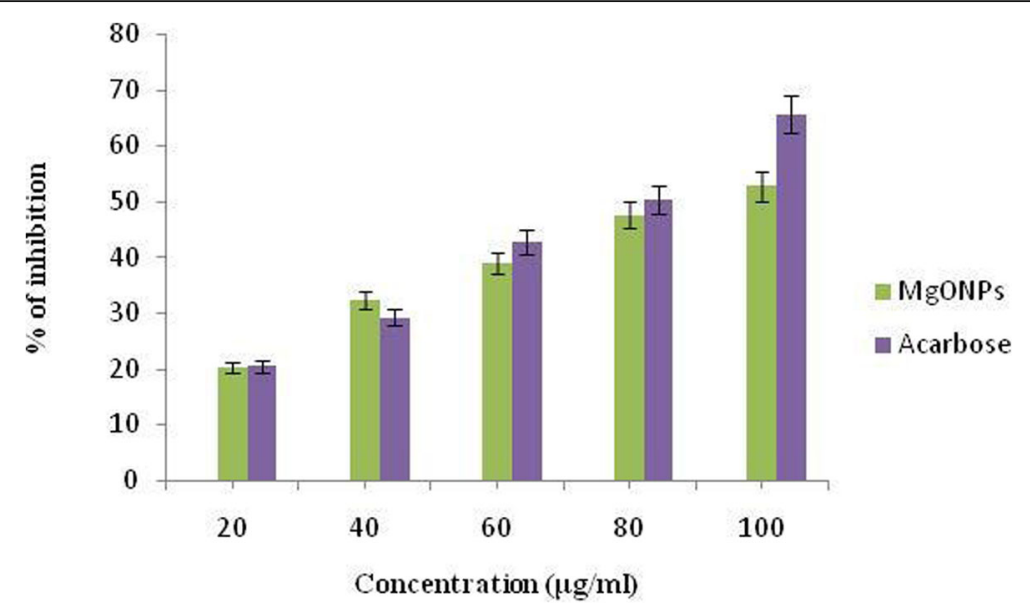

Fig. 9 Representing the percentage inhibition of alpha-amylase by biosynthesized MgO-NPs and Acarbose at different concentrations

study. The plants are rich in antioxidants with various phytochemicals involved in antioxidant activity by neutralizing reactive oxygen or free radicals, as antimicrobials, as anti-inflammatory, anti-diabetic, and so on [5]. Phenolic compounds present in plant extract with free hydrogen are primarily responsible for antioxidant activity [72]. Additionally, the significant antioxidant activity might be due to tannins, flavonoids, sugar reduction, polyphenols, and tannins [73].

Acetone, isopropyl alcohol, and ethanol heartwood extracts of Pterocarpus marsupium demonstrated excellent antioxidant activity in the radical scavenging system 2,2-diphenyl-1-picrylhydrazyl (DPPH) [74]. Methanol extract $(100 \mu \mathrm{g} / \mathrm{mL})$ of $P$. marsupium has the highest radical scavenging effect of 2,2-diphenyl1-picrylhydrazyl free radical followed by ethyl acetate and aqueous extracts. The scavenging effect reached saturation with extract concentration being further increased. This study showed substantial antioxidant activity in DPPH, superoxide, ABTS, hydroxyl radical, nitric oxide scavenging, and in vitro lipid peroxidation inhibition by $P$. marsupium heartwood extract [52]. Solanum trilobatum leaf extract synthesized $\mathrm{MgO}$ NPs have a slightly higher DPPH scavenging ability with IC50 72.24 $\mu \mathrm{g} \mathrm{mL}^{-1}$ relative to ascorbic acid (IC50 $33.46 \mu \mathrm{g} \mathrm{mL} \mathrm{m}^{-1}$ ). Sushma et al. [75] and Dobrucka et al. [58] reported antioxidant behavior of Clitoria ternatea leaf extract-mediated synthesis of MgO-NPs. The microbially synthesized MgO-NPs showed the maximum free radicals inhibition relative to the ones synthesized utilizing soil and chemical methods.

\section{Minimum inhibitory concentration}

Polyphenols and phenolics present in plants have been known to be harmful to micro-organisms [76]. Dichrostachys cinerea root bark tannin has antibacterial activity against Staphylococcus aureus, Escherichia coli, and Psuedomonas aeruginosa [77]. In vitro studies by Chung et al. [78] showed that tannins from different structures prevented the growth of the microorganism. Flavonoids have been documented as having both antibacterial and

Table 3 Alpha-amylase inhibitory activity by Pterocarpus marsupium synthesized MgO-NPs

\begin{tabular}{llll}
\hline Treatment & Concentration $(\boldsymbol{\mu g} / \mathbf{m L})$ & Percentage of inhibition $(\%)$ & $\mathbf{I C}_{\mathbf{5 0}}$ \\
\hline MgO-NPs synthesized with Pterocarpus marsupium & 20 & $20.23 \pm 1.11$ & $32.21 \pm 1.45$ \\
& 40 & $38.87 \pm 1.31$ \\
Acarbose & 60 & $47.56 \pm 1.45$ \\
& 80 & $52.72 \pm 1.52$ \\
& 100 & $20.45 \pm 1.01$ \\
& 20 & $29.23 \pm 1.54$ \\
& 40 & $42.65 \pm 1.56$ \\
& 60 & $50.37 \pm 1.87$ \\
\end{tabular}




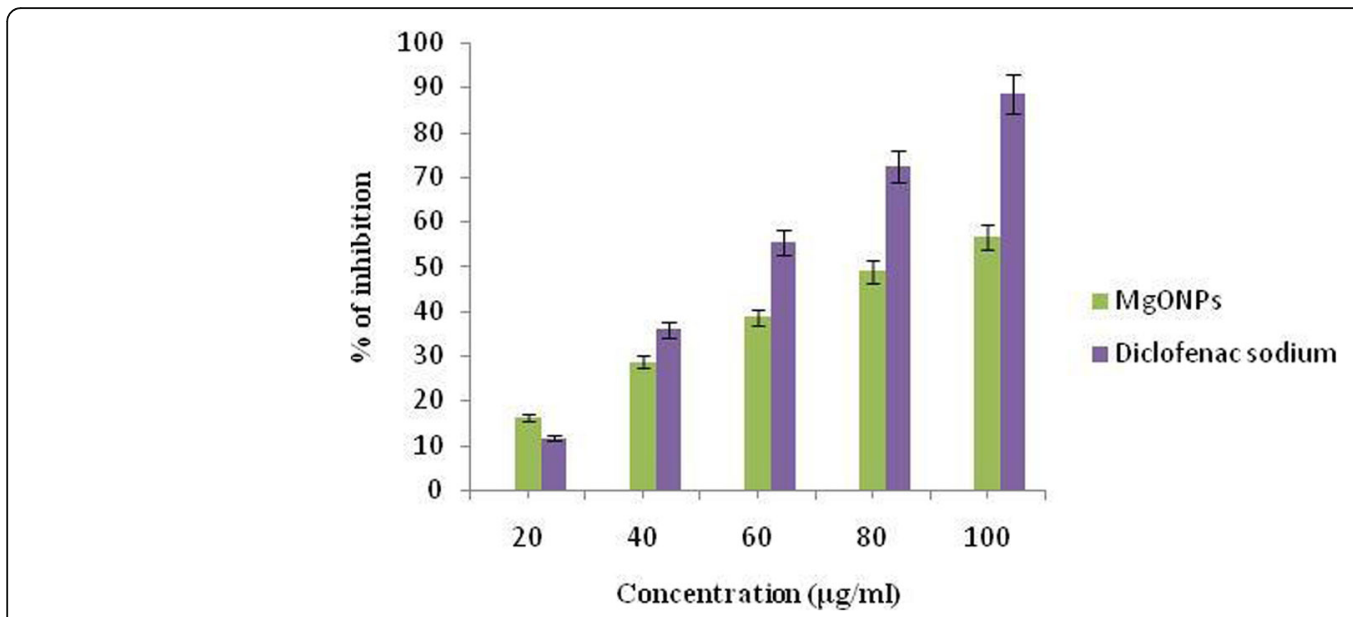

Fig. 10 Representing the albumin inhibitory activity calculated at different concentrations of biosynthesized MgO-NPs and Diclofenac sodium

antifungal activity [79]. Bijase et al. [80] have reported that isoflavonoids are isolated from the methanolic extract of root bark and stem bark of Bolusanthus specious exhibits antibacterial activity. Biologically active tannin glycosides, alkaloids, steroids, and flavonoids were found to contain the bark extract [81]. Among the majority of phytoconstituents that have potent antibacterial activity $[82,83]$, alkaloids also exhibit microbicidal action.

The suspension of phytoassisted magnesium oxide nanoparticles has probably shown significant antibacterial activity against $E$. coli and $S$. aureus because the MgO-NPs can easily reach the nucleus of the bacteria and provide an excellent surface area for interactions that impede development. Previous studies have reported the efficacy of MgO-NPs and other metallic nanoparticles on antibacterial behavior on the occurrence of oxygen vacancies on the surface of the nanoparticles, which contributed to lipid peroxidation and production of reactive oxygen species $[72,73]$. The antibacterial activity of the MgO-NPs against $E$. coli was also considered comparable with the silver/ $\mathrm{MgO}$ nanocomposites produced by using Musa paradisiaca extract [84]. The lipid peroxidation and reactive oxidative species production processes in the container have been responsible for the antibacterial ability of MgO-NPs [85]. Increased $\mathrm{pH}$ and $\mathrm{Mg}^{+}$ions have been predicted to play an important role in the mode of action of $\mathrm{MgO}$ nanoparticles against microbes, provided that $\mathrm{MgO}$ nanoparticles dissociate in microbial culture and release $\mathrm{OH}$-ions and $\mathrm{Mg}^{+}$ions [86].

Initial studies of metallic nanoparticles on their antimicrobial activities showed huge potential in the food industry, biomedical science, and many other science and technology sectors because these substances can offer enduring antibacterial activities due to their intrinsic instability and high-temperature tolerance properties [33]. Metallic nano component alternatives are important to significantly increase the magnitude and incidence of multidrug-resistant bacterial strains [87]. In an earlier study by Patil and Gaikwad [86], the P. marsupium stem bark

Table 4 Albumin denaturation activity by Pterocarpus marsupium synthesized MgO-NPs

\begin{tabular}{llll}
\hline Treatment & Concentration $(\boldsymbol{\mu g} / \mathbf{m L})$ & Percentage of inhibition $(\%)$ & $16.26 \pm 1.01$ \\
\hline MgO-NPs synthesized with Pterocarpus marsupium & 20 & $28.64 \pm 1.23$ \\
& 40 & $38.58 \pm 1.27$ \\
Diclofenac sodium & 60 & $48.92 \pm 1.54$ \\
& 80 & $56.53 \pm 1.31$ \\
& 100 & $11.63 \pm 1.02$ \\
& 20 & $35.89 \pm 1.37$ \\
& 40 & $55.45 \pm 1.43$ \\
& 60 & $72.38 \pm 1.54$ \\
\hline
\end{tabular}


(heartwood) methanolic extract showed the highest inhibitory effect against Pseudomonas aeruginosa followed by Bacillus subtili, S. aureus, Salmonella typhi, E. coli, Klebsiella pneumoniae, Micrococcus and Proteus mirabilis.

S. trilobatum-mediated MgO-NPs demonstrated significant antibacterial action against $E$. coli. Equally, Che-MgO-NPs exhibited maximal inhibition zone found in E. coli $(15.16 \pm 0.44 \mathrm{~mm})$ and total inhibitory zone in Streptococcus pyogenes (13.83 \pm 0.92 $\mathrm{mm})$ at a concentration of $100 \mathrm{mg} \mathrm{mL}^{-1}$ [69]. Doss et al. [88] demonstrated that MgO-NPs have antibacterial action against $E$. coli which was caused by a wide range of oxygen found on the magnesium surface. Doss et al. [88] and Krishnamoorthy et al. [89] described the increased antibacterial activity of magnesium NPs due to ROS and lipid peroxide with an oxygen defect present on particle morphology. $\mathrm{MgO}$ NPs, strong in electrostatic association with bacterial surface, contributed to cell death $[90,91]$.

\section{Alpha-amylase inhibitory activity of MgO-NPs}

Thus, it is revealed from inhibitory studies that the Pterocarpus marsupium-synthesized $\mathrm{MgO}$ nanoparticles are capable of inhibiting the alpha-amylase enzyme, which is additionally beneficial in delaying the break-down of starch into glucose, thereby controlling glucose rates in patients with diabetics. Jeevanandam [92] reported that $\mathrm{MgO}$ nanoparticles in diabetes mellitus can revert insulin resistance and be a strong antidiabetic agent. The ethanol extract of heartwood $(1 \mathrm{~g} / \mathrm{kg}$ oral and $2 \mathrm{~g} / \mathrm{kg}$ oral) greatly decreased the elevated rates of glucose in Wistar male albino rats with antidiabetic results in hyperglycemia and hyperinsulinemia triggered by dexamethasone [93]. Marsupsin and Pterostilbene are the Pterocarpus marsupium heartwood's most effective phenolic compounds after intraperitoneal administration using 40 $\mathrm{mg} / \mathrm{kg}$ b.wt for each dosage. The blood glucose level in hyperglycemic rats with hyperglycemia caused by streptozotocin, which is mainly useful in non-insulin-dependent diabetes mellitus (NIDDM) with obesity, decreased significantly aligned metformin as control [94].

Aqueous extract of Pterocarpus marsupium displayed a significant effect on reducing cytokine TNF$\alpha$ tested on streptozotocin-induced rats. Cytokine TNF- $\alpha$ was initially elevated in uncontrolled diabetic rats owing to chronic systemic inflammation. Both doses of aqueous extract (100 and $200 \mathrm{mg} / \mathrm{kg}$ b.wt.) appreciably reduced the increased TNF- $\alpha$ level in rats due to the isoflavone components in plant aqueous extract [95].

\section{Effect on protein inhibition}

$P$. marsupium aqueous extract was observed to reduce elevated inflammatory cytokine, TNF- $\alpha$ rates in
NIDDM diabetic rats at doses of $100 \mathrm{mg} / \mathrm{kg}$ and 200 $\mathrm{mg} / \mathrm{kg}$ b.wt [52]. Methanol and aqueous extract of $P$. marsupium used carrageenan-mediated rat paw edema approach to test anti-inflammatory activity by the model of acute inflammation. The dosage of methanol extract $50 \mathrm{mg} / \mathrm{kg}$ b.wt. and dosage of aqueous extract of $100 \mathrm{mg} / \mathrm{kg}$ b.wt. reported a significant decline in paw edema. Both extracts were found to have significant anti-inflammatory activity [96]. Nano-MgO showed stronger analgesic and antiinflammatory activities in mice at experimental formalin and acetic acid tests [97].

\section{Conclusion}

In the present study, we have reported phytoassisted synthesis of magnesium-oxide nanoparticles using Pterocarpus marsupium heartwood extract. The organic molecules in the aqueous extract act as reducing and stabilizing agents. The MgO-NPs have been characterized using UV, DLS, FT-IR, XRD, SEM, and TEM. Magnesium oxide nanoparticles formation was confirmed by a sharp absorption peak at $310 \mathrm{~nm}$. FTIR analysis proves the formation of $\mathrm{MgO}$ nanoparticles by the functional groups of $P$. marsupium that act as reducing and stabilizing agents. The average size $(16.76 \mathrm{~nm})$ of $\mathrm{MgO}-\mathrm{NP}$, which was determined from the Debye Scherer formula, was found by XRD analysis. The observed MgO-NPs is spherically shaped with nanometer size is confirmed in SEM and TEM. EDS analysis has identified the chemical composition of $\mathrm{MgO}$ nanoparticles. The antioxidant activity of MgO-NPs was evaluated using DPPH scavenging activity and the $\mathrm{IC}_{50}$ value of the MgO-NPs was found to be $89.67 \mu \mathrm{g} / \mathrm{mL}$. The antibacterial activity of $\mathrm{MgO}$ NPs was calculated by using minimum inhibitory concentration assay against Gram-positive and Gramnegative bacteria and the MIC values obtained are 22 \pm 0.168 and $24 \pm 0.439 \mu \mathrm{g} / \mathrm{mL}$. The antidiabetic activity of phytoassisted MgO-NPs was tested on inhibition of $\alpha$-amylase; the $\mathrm{IC}_{50}$ was found to be 56.32 . The anti-inflammatory activity of $\mathrm{MgO}-\mathrm{NPs}$ was tested by the albumin denaturation method; the $\mathrm{IC}_{50}$ value was found to be 81.69 . Thus magnesium oxide nanoparticles synthesized from $P$. marsupium obtained may have possible biomedical applications showing excellent antioxidant, antibacterial, antidiabetic, and anti-inflammatory properties.

\section{Abbreviations}

PM: Pterocarpus marsupium; MgO-NPs: Magnesium oxide nanoparticles; MgO: Magnesium oxide; NPs: Nanoparticles; UV-Vis: UV-Visible spectrophotometry; PDI: Polydispersity index; XRD: X-ray diffraction; FTIR: Fourier transform infrared spectroscopy; SEM: Scanning electron microscopy; EDS: Energy-dispersive X-ray spectroscopy; TEM: Transmission electron microscopy; DLS: Dynamic light scattering; SAED: Selected area electron diffraction; $\mathrm{IC}_{50}$ : Half-maximal inhibitory concentration 


\section{Acknowledgement}

The authors of the article are thankful to Department of Biotechnology, Acharya Nagarjuna University, for providing the research facilities.

\section{Authors' contributions}

MAA conducted the research and writing of the manuscript. AKG has assisted, analyzed the data, and performed initial drafting of the manuscript, and WK executed the experimental works and analyzed data. VPK and UM for their assistance with study administration. SP was responsible for designing the research and approving the final content of the manuscript. All the authors have read and approved the final manuscript.

\section{Funding}

Not applicable.

\section{Availability of data and materials}

Not applicable.

Ethics approval and consent to participate

Not applicable.

\section{Consent for publication}

Not applicable.

\section{Competing interests}

The authors declare that they have no competing interests.

\section{Author details}

'Department of Biotechnology, Acharya Nagarjuna University, Nagarjuna Nagar, Guntur, Andhra Pradesh 522510, India. Freshman Engineering Department, PVP Siddhartha Institute of Technology, Chalasani Nagar, Kanuru, Vijayawada, Andhra Pradesh 520007, India. ${ }^{3}$ Department of Biotechnology, Koneru Lakshmaiah Education Foundation, Guntur, Andhra Pradesh, India. ${ }^{4}$ Department of Botany and Microbiology, Acharya Nagarjuna University, Nagarjuna Nagar, Guntur, Andhra Pradesh 522510, India.

\section{Received: 20 November 2020 Accepted: 11 January 2021}

\section{Published online: 28 January 2021}

\section{References}

1. Abdelghany TM, Al-Rajhi AMH, Al Abboud MA et al (2018) Recent advances in green synthesis of silver nanoparticles and their applications: about future directions-a review. Bionanoscience 8:5-16

2. Irshad R, Tahir K, Li B, Ahmad A, Siddiqui AR, Nazir S (2017) Antibacterial activity of biochemically capped iron oxide nanopartciles: a view towards green chemistry. J Photochem Photobiol B 170:241-246. https://doi.org/10. 1016/j.jphotobiol.2017.04.020

3. Mirzaei H, Davoodnia A (2012) Microwave-assisted sol-gel synthesis of MgO nanoparticles and their catalytic activity in the synthesis of hantzsch 1, 4dihydropyridines. Chin J Catal 33:1502-1507

4. Kalaiarasi R, Jayallakshmi N, Venkatachalam P (2010) Phytosynthesis of nanoparticles and its applications. Plant Cell Biotechnol Mol Biol 11:1-16

5. Jeevanandam J, Chan YS, Danquah MK (2016) Biosynthesis of metal and metal oxide nanoparticles. Chem Bio Eng. https://doi.org/10.1002/cben. 201500018

6. Iravani S (2014) Bacteria in nanoparticle synthesis: current status and future prospects. Int Sch Res Notices. https://doi.org/10.1155/2014/359316

7. Sastry M, Ahmad A, Khan MI, Kumar R (2003) Biosynthesis of metal nanoparticles using fungi and actinomycete. Curr Sci 85(2):162-170

8. Hulkoti NI, Taranath T (2014) Biosynthesis of nanoparticles using microbes-review. Colloids Surf B 121:474-483. https://doi.org/10.1016/j. colsurfb.2014.05.027

9. Makarov V, Love A, Sinitsyna O, Makarova S, Yaminsky I, Taliansky M, Kalinina N (2014) Green nanotechnologies: synthesis of metal nanoparticles using plants. Acta Naturae 6:35-44

10. Iravani S (2011) Green synthesis of metal nanoparticles using plants. Green Chem 13:2638-2650. https://doi.org/10.1039/C1GC15386B

11. Emmanuel R, Palanisamy S, Chen SM, Chelladurai K, Padmavathy S, Saravanan M, Prakash P, Ali MA, Al-Hemaid FM (2015) Antimicrobial efficacy of green synthesized drug blended silver nanoparticles against dental caries and periodontal disease causing microorganisms. Mater Sci Eng 56:374-379
12. Gour A, Jain NK (2019) Advances in green synthesis of nanoparticles. Artif Cells Nanomed Biotechnol 47(1):844-851. https://doi.org/10.1080/21691401. 2019.1577878

13. Subhan A, Irshad R, Nazir S, Tahir K, Ahmad A, Khan AU, Khan ZUIH (2019) A new study of biomediated Pd/tiO2: a competitive system for Escherichia coli inhibition and radical stabilization. Mater Res Express 6:125430. https://doi. org/10.1088/2053-1591/ab5eaa

14. Rafique M, Sadaf I, Rafique MS et al (2017) A review on green synthesis of silver nanoparticles and their applications. Artif Cells Nanomed Biotechnol 45:1272-1291

15. Nguyen NHA, Padil WT, Slaveykova VI, Cernik M, Sevcu A (2018) Green synthesis of metal and metal oxide nanoparticles and their effect on the Unicellular alga Chlamydomonas reinhardtii. Nanoscale Res Lett 13:159. https://doi.org/10.1186/s11671-018-2575-5

16. Varma RS (2012) Greener approach to nanomaterials and their sustainable applications. Curr Opin Chem Eng 1:123-128

17. Singh J, Kumar V, Kim K-H, Rawata M (2019) Biogenic synthesis of copper oxide nanoparticles using plant extract and its prodigious potential for photocatalytic degradation of dyes. Environ Res 177:108569

18. Mathur P, Jha S, Ramteke S et al (2017) Pharmaceutical aspects of silver nanoparticles. Artif Cells Nanomed Biotechnol 46:1-12

19. Liang SH, Gay ID (1986) A carbon-13 solid-state NMR study of the chemisorption and decomposition of ethanol on magnesium oxide. J Catal 101(2):293-300

20. Tsuji H, Yagi F, Hattori H, Kita H (1994) Self-condensation of $n$ butyraldehyde over solid base catalysts. J Catal 148(2):759-770

21. Hussain AA, Nazir S, Irshad R, Tahir K, Raza M, Khan ZUIH, Khan AU (2020) Synthesis of functionalized mesoporous Ni-SBA-16 decorated with MgO nanoparticles for $\mathrm{Cr}(\mathrm{VI})$ adsorption and an effective catalyst for hydrodechlorination of chlorobenzene. Mater Res Bull 133:111059. https:// doi.org/10.1016/j.materresbull.2020.111059

22. Bhargava A, Alarco JA, Mackinnon ID, Page D, llyush-echkin A (1998) Synthesis and characterisation of nanoscale magnesium oxide powders and their application in thick films of $\mathrm{Bi}_{2} \mathrm{Sr}_{2} \mathrm{CaCu}_{2} \mathrm{O}_{8}$. Mater Lett 34(3-6):133-142

23. Yuan YS, Wang SS (1996) Solid-state processing and phase development of bulk (MgO)w/BPSCCO high-temperature superconducting composite. J Mater Res 11(1):8-17

24. Yang PD, Lieber CM (1996) Nanorod-superconductor composites: a pathway to high critical current density materials. Science 273:1836-1849

25. Kaur J, Singh J, Rawat M (2019) An efficient and blistering reduction of 4nitrophenol by green synthesized silver nanoparticles. SN Appl Sci 1:1060. https://doi.org/10.1007/s42452-019-1088-x

26. Singh J, Kumar V, Jolly SS, Kim K-H, Rawata M, Kukkara D, Tsange YF (2019) Biogenic synthesis of silver nanoparticles and its photocatalytic applications for removal of organic pollutants in water. J Industr Eng Chem 80:247-257

27. Singh J, Mehta A, Rawata M, Basub S (2018) Green synthesis of silver nanoparticles using sun dried tulsi leaves and its catalytic application for 4Nitrophenol reduction. J Environ Chem Eng 6:1468-1474

28. Singh J, Kukkar P, Sammi H, Rawat M, Singh G, Kukkar D (2017) Enhanced catalytic reduction of 4-nitrophenol and congo red dye By silver nanoparticles prepared from Azadirachta indica leaf extract under direct sunlight exposure. Particul Sci Technol. https://doi.org/10.1080/02726351. 2017.1390512

29. Singh K, Kukkar D, Singh R, Kukkar P, Bajaj N, Singh J, Rawat M, Kumar A Kim K-H (2020) In situ green synthesis of Au/Ag nanostructures on a metalorganic framework surface for photocatalytic reduction of p-nitrophenol. J Industr Eng Chem 81:196-205. https://doi.org/10.1016/j.jiec.2019.09.008

30. Rawat M, Singh J, Singh J, Singh C, Singh A, Kukkar D, Kumar S (2017) Synthesis of Cu and Ce-doped ZnO nanoparticles: crystallographic, optical, molecular, morphological and magnetic studies. Mater Sci 35(2). https://doi. org/10.1515/msp-2017-0040

31. Kaur S, Singh J, Rawat R et al (2018) A smart LPG sensor based on chemobio synthesized MgO nanostructure. J Mater Sci 29:11679-11687. https://doi. org/10.1007/s10854-018-9266-y

32. Stoimenov PK, Klinger RL, Marchin GL, Klabunde KJ (2002) Metal oxide nanoparticles as bacterial agents. Langmuir 18:6679-6686

33. Lin ST, Klabunde JK (1985) Thermally activated magnesium oxide surface chemistry. Adsorption and decomposition of phosphorus compounds. Langmuir 1(5):600-605

34. Moorthy SK, Ashok CH, Venkateswara Rao K, Viswanathan C (2015) Synthesis and characterization of $\mathrm{MgO}$ nanoparticles by Neem leaves through green method. Mater Today Proc 2:4360-4368 
35. Kumar D, Reddy Yadav LS, Lingaraju K, Manjunath K, Suresh D, Prasad D, Nagabhushana H, Sharma SC, Raja Naika H, Chikkahanumantharayappa NG (2015) Combustion synthesis of MgO nanoparticles using plant extract: structural characterization and photoluminescence studies. AIP Conf Proc 1665:050145

36. Awwad AM, Ahmad AL (2014) Biosynthesis, characterization, and optical properties of magnesium hydroxide and oxide nanoflakes using Citrus limon leaf extract. Arab J Phys Chem 1(2):66

37. Sugirtha P, Divya R, Yedhukrishnan R, Suganthi KS, Anusha N, Ponnusami V, Rajan KS (2015) Green synthesis of magnesium oxide nanoparticles using Brassica oleracea and Punica granatum peels and their anticancer and photocatalytic activity. Asian J Chem 27(7):2513-2517

38. Gupta P, Jain V, Pareek A, Kumari P, Singh R, Agarwal P, Sharma V (2017) Evaluation of effect of alcoholic extract of heartwood of Pterocarpus marsupium on in vitro antioxidant, anti-glycation, sorbitol accumulation and inhibition of aldose reductase activity. J Tradition Complement Med:307314

39. Rani P, Kaur G, Rao KV et al (2020) Impact of green synthesized metal oxide nanoparticles on seed germination and seedling growth of Vigna radiata (Mung Bean) and Cajanus cajan (Red Gram). J Inorg Organomet Polym. https://doi.org/10.1007/s10904-020-01551-4

40. Singh J, Kumar S, Alok A, Upadhyay SK, Rawat M, Tsang DCW, Bolan N, Kim K-H (2019) The potential of green synthesized zinc oxide nanoparticles as nutrient source for plant growth. J Clean Product 214:1061-1070

41. Gholami-Shabani M, Shams-Ghahfarokhi M, Gholami-Shabani Z et al (2015) Enzymatic synthesis of gold nanoparticles using sulfite reductase purified from Escherichia coli: a green eco-friendly approach. Process Biochem 50: 1076-1085

42. Adelere IA, Lateef A (2016) A novel approach to the green synthesis of metallic nanoparticles: the use of agro-wastes, enzymes, and pigments. Nanotechnol Rev 5:567-587

43. Singh J, Dutta T, Kim K et al (2018) Green synthesis of metals and their oxide nanoparticles: applications for environmental remediation. J Nanobiotechnol 16(84). https://doi.org/10.1186/s12951-018-0408-4

44. Prathna TC, Mathew L, Chandrasekaran N et al (2010) Biomimetic synthesis of nanoparticles: science, technology and applicability. Biomimetics Learn Nat. https://doi.org/10.5772/8776

45. Ahmad N, Sharma S, Alam MK et al (2010) Rapid synthesis of silver nanoparticles using dried medicinal plant of basil. Colloids Surf B Biointerfaces 81:81-86. https://doi.org/10.1016/j.colsurfb.2010.06.029

46. Rajgovind G, Sharma DK, Gupta ND, Jasuja SC, Joshi C (2015) Pterocarpus marsupium derived phyto-synthesis of copper oxide nanoparticles and their antimicrobial activities. J Microb Biochem Technol 7:140-144

47. Perera HK (2016) Antidiabetic effects of Pterocarpus marsupium. Eur J Med Plants 13(4):1-14

48. Maruthupandian A, Mohan VR (2011) Antidiabetic, Antihyperlipidaemic and Antioxidant activity of Pterocarpus marsupium Roxb. in alloxan induced diabetic rats. Int J Pharma Techchnol 3(3):1681-1687

49. Rajeeb M, Usman M, Pathan EK, Jain BV, Pawar SR (2018) Ethnobotanical uses, phytochemistry and pharmacological activities of Pterocarpus marsupium. A review of Ph and Sci Innov, pp 1-5. https://doi.org/10.5530/pj.2018.6s.1

50. Manickam M, Ramanathan M, Farboodniay Jahromi MA, Chansouria JP, Ray AB (1997) Antihyperglycemic activity of phenolics from Pterocarpus marsupium. J Nat Prod 60(6):609-610

51. Rastogi RP, Mehrotra BN (1982) Compendium of Indian medicinal plants, vol 1993. PID, New Delhi, p 537

52. Pant DR, Pant ND, Saru DB, Yadav UN, Khanal DP (2017) Phytochemical screening and study of antioxidant, antimicrobial, antidiabetic, antiinflammatory and analgesic activities of extracts from stem wood of Pterocarpus marsupium Roxburgh. J Intercult Ethnopharmacol 6(2):170

53. Vergheese M, Kiran Vishal S (2018) Green synthesis of magnesium oxide nanoparticles using Trigonella foenum-graecum leaf extract and its antibacterial activity. J Pharmacogn Phytochem 7(3):1193-1200

54. Das B, Moumita S, Ghosh S, Khan MI, Indira O, Jayabalan R, Tripathy SK, Mishra A, Balasubramanian P (2018) Biosynthesis of magnesium oxide $\mathrm{MgO}$ ) nanoflakes by using leaf extract of Bauhinia purpurea and evaluation of its antibacterial property against Staphylococcus aureus. Mater Sci Eng. https://doi.org/10.1016/j.msec.2018.05.059

55. Chang CC, Yang MH, Wen HM, Chern JC (2002) Estimation of total flavonoid content in propolis by two complementary colorimetric methods. J Food Drug Anal 10(3):178-182
56. Sharma G, Soni R, Jasuja ND (2018) Phytoassisted synthesis of magnesium oxide nanoparticles with Swertia chirayaita. J Taibah Univ Sci 11(3):471-477. https://doi.org/10.1016/j.jtusci.2016.09.004

57. Perveen S, Safdar N, Chaudhry G-e-s, Yasmin A (2018) Antibacterial evaluation of silver nanoparticles synthesized from lychee peel: individual versus antibiotic conjugated effects. World J Microbiol Biotechnol 34:118

58. Dobrucia R (2018) Synthesis of MgO nanoparticles using Artemisia abrotanum herba extract and their antioxidant and photocatalytic properties. Iran J Sci Technol Trans Sci 42:547-555. https://doi.org/10.1007/ s40995-016-0076-x

59. Ammulu MA, Vinay Viswanath K, Ajay Kumar G, Mangamuri U, Poda S (2020) Pterocarpus marsupium Rox b. heartwood extract synthesized chitosan nanoparticles and its biomedical applications. J Genet Eng Biotechnol. https://doi.org/10.1186/s43141-020-00033-x

60. Meva FE, Mbeng JO, Ebongue CO, Schlüsener C, Kokcam-Demir U, Ntoumba AA, Kedi PB, Elanga E, Loudang ER, Nkoo MH, Tchoumbi E, Deli V, Nanga CC, Mpondo EA, Janiak C (2019) Stachytarpheta cayennensis aqueous extract, a new bioreactor towards silver nanoparticles for biomedical applications. J Biomater Nanobiotechnol 10:102-119. https://doi.org/10. 4236/jbnb.2019.102006

61. Safaei-Ghomia J, Zahedia S, Javida M, Ghasemzadeh MA (2015) MgO nanoparticles: an efficient, green and reusable catalyst for the one-pot syntheses of 2,6-dicyanoanilines and 1,3-diarylpropyl malononitriles under different conditions. J Nanostruct 5:153-160

62. Khan Ml, Akhtar MN, Ashraf N et al (2020) Green synthesis of magnesium oxide nanoparticles using Dalbergia sissoo extract for photocatalytic activity and antibacterial efficacy. Appl Nanosci 10:2351-2364. https://doi.org/10. 1007/s13204-020-01414-X

63. Jeevanandam J, Chan YS, Danquah MK (2017) Biosynthesis and characterization of $\mathrm{MgO}$ nanoparticles from plant extracts via induced modified nucleation. New J Chem. https://doi.org/10.1039/C6NJ03176E

64. Tamilselvi P, Yelilarasi A, Hema M, Anbarasan R (2013) Synthesis of hierarchical structured MgO by sol-gel method. Nano Bull 2:130106

65. Ahmad H, Rajgopal K (2015) Pharmacology of Pterocarpus marsupium Roxb. Med Plant Res 5(3). https://doi.org/10.5376/mpr.2015.05.0003

66. Gaumet M, Vargas A, Gurny R, Delie F (2008) Nanoparticles for drug delivery: the need for precision in reporting particle size paramaters. Eur J Pharm Biopharm 69:1-9. https://doi.org/10.1016/j.ejpb.2007.08.001

67. Essien R, Astasie VN, Okeafor AO, Nwude DO (2019) Biogenic synthesis of magnesium oxide nanoparticles using Manihot esculenta (Crantz) leaf extract. Int Nano Lett. https://doi.org/10.1007/s40089-019-00290-w

68. Navalon S, Garcia H (2016) Nanoparticles for catalysis. Nanomater 6:123. https://doi.org/10.3390/nano6070123

69. Narendhran S, Manikandan M, Baby Shakila P (2019) Antibacterial, antioxidant properties of Solanum trilobatum and sodium hydroxidemediated magnesium oxide nanoparticles: a green chemistry approach. Bull Mater Sci 42:133. https://doi.org/10.1007/s12034-019-1811-7

70. Jeevanandam J, Chan YS, Danquah MK (2019) Effect of pH variations on morphological transformation of biosynthesized MgO nanoparticles. Particul Sci Technol:1548-0046. https:/doi.org/10.1080/02726351.2019.1566938

71. Essien ER, Atasie VN, Oyebanji TO et al (2020) Biomimetic synthesis of magnesium oxide nanoparticles using Chromolaena odorata (L.) leaf extract. Chem Pap 74:2101-2109. https://doi.org/10.1007/s11696-020-01056-x

72. Subba B, Srivastav C, Kandel RC (2016) Scientific validation of medicinal plants used by Yakkha community of Chanuwa VDC, Dhankuta, Nepal. Springerplus 5:155

73. Patel MB, Mishra SM (2009) Aldose reductase inhibitory activity and anti catraract potential of some traditionally acclaimed antidiabetic medicinal plants. Orient Pharm Exp Med 9:245-251

74. Abirami B, Gayathri P, Uma D (2012) In vitro antioxidant potential of Pterocarpus marsupium bark. Int J Chem Pharm Sci 3:17-24

75. Sushma NJ, Prathyusha D, Swathi G et al (2016) Facile approach to synthesize magnesium oxide nanoparticles by using Clitoria ternatea characterization and in vitro antioxidant studies. Appl Nanosci 6(3):437-444

76. Ullah S, Ahmad A, Wang A, Raza M, Jan AU, Tahir K, Rahman AU, Qipeng Y (2017) Biofabrication of catalytic platinum nanoparticles and their in vitro efficacy against lungs cancer cells line (A549). J Photochem Photobiol B 173: 368-375. https://doi.org/10.1016/j.jphotobiol.2017.06.018

77. Banso A, Adeyama SO (2007) Evaluation of antibacterial properties of tannins isolated from Dichrostachys cinerea. Afr J Biotech 6(15):1785-1787

78. Chung KT, Wong TY, Wei Cl, Huang YW, Lin Y (1998) Tannins and human health: a review. Crit Rev Food Sci Nutr 38:421-464 
79. Tsuchiya H, Sato M, Miuazaki T, Fujiwara S, Tanigaki S (1996) Comparative study on the antibacterial activity of phytochemical flavonones against methicillin resisitant Staphylococcus aureus. J Ethnopharmacol 50:27-34

80. Bijase G, Majinda RR, Gashe BA, Wanjala CC (2002) Antimicrobial flavonoids from Bolusanthus speciosus. Planta Med 68(7):615-620

81. Shimada T (2006) Salivary proteins as a defense against dietary tannins. J Chem Ecol 32(6):1149-1163

82. Sarkar SD, Muniruzzaman S, Khan SI (1991) Antimicrobial activity of Piper Chaba Hunter (Chui). Bangladesh J Bot 20:179-182

83. Adekunle A, Ikumapayi AM (2006) Antifungal property and phytochemical screening of the crude extracts of Funtumia elastica and Mallotus oppositifolius. West Indian Med J 55(4):223

84. Jayapriya M, Premkumar K, Arulmozhi M, Karthikeyan K (2020) One-step biological synthesis of caulifower-like $\mathrm{Ag} / \mathrm{MgO}$ nanocomposite with antibacterial, anticancer, and catalytic activity towards anthropogenic pollutants. Res Chem Intermed 46:1771-1788. https://doi.org/10.1007/ s11164-019-04062-1

85. Umaralikhan L, Jafar MJ (2018) Green synthesis of MgO nanoparticles and it antibacterial activity. Iran J Sci Technol A 42:477-485

86. Patil UH, Gaikwad DK (2011) Phytochemical screening and microbicidal activity of stem bark of Pterocarpus marsupium. Int J Pharma Sci Res 2(1):3640

87. Ekerdt JG, Klabunde KJ, Shapley JR, White JM, Yates JT (1988) Surface chemistry of organophosphorus compounds. J Phys Chem 92(22):61826188

88. Doss A, Muhamed MH, Dhanabalan R (2009) Antibacterial activity of tannins from the leaves of Solanum trilobatum Linn. Indian J Sci Tech 2(2):41-43

89. Krishnamoorthy K, Manivannan G, Kim SJ, Jeyasubramanian K, Premanathan M (2012) Antibacterial activity of $\mathrm{MgO}$ nanoparticles based on lipid peroxidation by oxygen vacancy. J Nanoparticle Res 14:1063. https://doi. org/10.1007/s11051-012-1063-6

90. Stoimenov PK, Klinger RL, Marchin GL, Klabunde KJ (2002) Metal oxide nanoparticles as Bactericidal agents. Langmuir 18(17):6679-6686. https://doi. org/10.1021/la0202374

91. Sundrarajan M, Suresh J, Gandhi RR (2012) A comparative study on antibacterial properties of Mgo nanoparticles prepared under different calcination temperature. Dig J Nanomater Biostruct 7:983-989

92. Jeevanandam J, Danquah MK, Debnath S, Meka VS, Chan YS (2015) Opportunities for nano-formulations in type 2 diabetes mellitus treatments. Curr Pharm Biotechnol 16(10):853-870. https://doi.org/10.2174/ 1389201016666150727120618

93. Narendar K, Nayak MN, Jamadar MG, Patil AM, Anand S (2016) Comparison of the effect of Pterocarpus marsupium with Pioglitazone in dexamethasone-induced insulin resistance. Asian J Pharm Clin Res 9(2):211214

94. Jahromi MF, Ray AB, Chansouria JP (1993) Antihyperlipidemic effect of flavonoids from Pterocarpus marsupium. J Nat Prod 56(7):989-994

95. Halagappa K, Girish HN, Srinivasan BP (2010) The study of aqueous extract of Pterocarpus marsupium Roxb. on cytokine TNF-a in type 2 diabetic rats. Indian J Pharmacol 42(6):392-396

96. Rahman MS, Mujahid MD, Siddiqui MA, Rahman MS, Arif M, Eram S, Khan A, Azeemuddin MD (2018) Ethnobotanical uses, phytochemistry and pharmacological activities of Pterocarpus marsupium: a review. Pharmacog J 10(6):s1-s8. https://doi.org/10.5530/pj.2018.6s.1

97. Kesmati M, Najafzadeh H (2013) Evaluation of analgesic and antiinflammatory effect of nanoparticles of magnesium oxide in mice with and without ketamine. Eur Rev Med Pharmacol Sci 17(20):2706-2710

\section{Publisher's Note}

Springer Nature remains neutral with regard to jurisdictional claims in published maps and institutional affiliations.

\section{Submit your manuscript to a SpringerOpen ${ }^{\circ}$ journal and benefit from:}

- Convenient online submission

- Rigorous peer review

- Open access: articles freely available online

High visibility within the field

- Retaining the copyright to your article

Submit your next manuscript at $\boldsymbol{\nabla}$ springeropen.com 